\title{
Evaluating the capabilities and uncertainties of droplet measurements for the fog droplet spectrometer (FM-100)
}

\author{
J. K. Spiegel ${ }^{1}$, P. Zieger ${ }^{2}$, N. Bukowiecki ${ }^{2}$, E. Hammer ${ }^{2}$, E. Weingartner ${ }^{2}$, and W. Eugster ${ }^{1}$ \\ ${ }^{1}$ ETH Zurich, Institute for Agricultural Sciences, Universitätstrasse 2, 8092 Zurich, Switzerland \\ ${ }^{2}$ Paul Scherrer Institute, Laboratory of Atmospheric Chemistry, 5232 Villigen PSI, Switzerland
}

Correspondence to: W. Eugster (eugsterw@ethz.ch)

Received: 30 March 2012 - Published in Atmos. Meas. Tech. Discuss.: 7 May 2012

Revised: 21 August 2012 - Accepted: 24 August 2012 - Published: 20 September 2012

\begin{abstract}
Droplet size spectra measurements are crucial to obtain a quantitative microphysical description of clouds and fog. However, cloud droplet size measurements are subject to various uncertainties. This work focuses on the error analysis of two key measurement uncertainties arising during cloud droplet size measurements with a conventional droplet size spectrometer (FM-100): first, we addressed the precision with which droplets can be sized with the FM-100 on the basis of the Mie theory. We deduced error assumptions and proposed a new method on how to correct measured size distributions for these errors by redistributing the measured droplet size distribution using a stochastic approach. Second, based on a literature study, we summarized corrections for particle losses during sampling with the FM-100. We applied both corrections to cloud droplet size spectra measured at the high alpine site Jungfraujoch for a temperature range from $0^{\circ} \mathrm{C}$ to $11^{\circ} \mathrm{C}$. We showed that Mie scattering led to spikes in the droplet size distributions using the default sizing procedure, while the new stochastic approach reproduced the ambient size distribution adequately. A detailed analysis of the FM-100 sampling efficiency revealed that particle losses were typically below $10 \%$ for droplet diameters up to $10 \mu \mathrm{m}$. For larger droplets, particle losses can increase up to $90 \%$ for the largest droplets of $50 \mu \mathrm{m}$ at ambient wind speeds below $4.4 \mathrm{~m} \mathrm{~s}^{-1}$ and even to $>90 \%$ for larger angles between the instrument orientation and the wind vector (sampling angle) at higher wind speeds. Comparisons of the FM-100 to other reference instruments revealed that the total liquid water content (LWC) measured by the FM-100 was more sensitive to particle losses than to re-sizing based on Mie scattering, while the total number concentration was only marginally influenced by particle losses. Consequently, for further LWC
\end{abstract}

measurements with the FM-100 we strongly recommend to consider (1) the error arising due to Mie scattering, and (2) the particle losses, especially for larger droplets depending on the set-up and wind conditions.

\section{Introduction}

The cloud droplet size distribution is one of the key parameter for a quantitative microphysical description of clouds (e.g. Pruppacher and Klett, 1997). It plays an important role for the radiative characteristic of the cloud and is, for example needed to describe the anthropogenic influence (Gunn and Philips, 1957; Twomey, 1977) and the cloud lifetime effect (Albrecht, 1989; Rosenfeld and Lensky, 1998). Moreover, the knowledge of droplet size distribution is crucial for a better understanding of the onset of precipitation (Gunn and Philips, 1957; Stevens and Feingold, 2009) as well as the occult deposition input of clouds to vegetation, which is known to be a relevant component in the hydrological budget of tropical mountain cloud forests (Bruijnzeel et al., 2005; Eugster et al., 2006). At this stage, there are two different approaches of measuring cloud droplet sizes: in-situ measurements using optical instruments on aircrafts or ground based stations (e.g. Knollenberg, 1981; Baumgardner, 1983; Baumgardner et al., 2003) and inverse retrieval techniques based on remote sensing measurements from satellites (e.g. Bennartz et al., 2011; Kokhanovsky and Rozanov, 2012). Although in-situ measurements have intrinsic difficulties, they are considered to be the best available method for measuring cloud droplets (Miles et al., 2000). The basic working principle for the size detection used in these devices is 
forward scattering of light, which was first mathematically solved by Gustav Mie (Mie, 1908). The first commercial available optical instrument for in-situ droplet measurements was build in the 1970s (Pinnick and Auvermann, 1979). The instruments have been developed further and their performance has been strongly improved in terms of precision and automatization since then. Today, a variety of instruments based on forward scattering are in use: the Forward Scattering Spectrometer Probe (FSSP; capable of measuring hydrometeors with diameters $D=2$ to $50 \mu \mathrm{m}$, e.g. Pinnick and Auvermann, 1979), the Cloud Droplet Probe (CDP; Model CDP-100, $D=2$ to $50 \mu \mathrm{m}$, e.g. McFarquhar et al., 2007), the Cloud and Aerosol Spectrometer - also with Depolarization CAS-DPOL - (CAS and CAS-DPOL; $D=0.5$ to $50 \mu \mathrm{m}$, Baumgardner et al., 2011), the Cloud Particle Spectrometer with Depolarization (CPSD; $D=0.5$ to $50 \mu \mathrm{m}$, Baumgardner et al., 2011), the Small Ice Detectors (SID model 1 and 2; $D=2$ to $140 \mu \mathrm{m}$, Baumgardner et al., 2011) and the Fog Monitor 100 (FM-100; $D=2$ to $50 \mu \mathrm{m}$, e.g. Burkard et al., 2002). Using light scattering interferometry, cloud droplets can also be measured in size, for example with the Phase Doppler Interferometer (PIP; 1 to $1000 \mu \mathrm{m}$, Baumgardner et al., 2011). However, for realistic operations a reasonable upper-bound was found to be $D \approx 100 \mu \mathrm{m}$ (Chuang et al., 2008). Furthermore, imaging techniques can be used to capture the cloud's particle images. Beyond others, a Cloud Particle Imager (CPI; SPEC Inc. Model 230X, Connolly et al., 2007) can be deployed to observe and record real-time CCD images (8-bit, gray-scale $1024 \times 1024$ pixels with a pixel resolution of $2.3 \mu \mathrm{m}$ ) of the ice particles and supercooled droplets with $D=10$ to $2300 \mu \mathrm{m}$ present in the clouds. From these images, the ice crystal number and mass concentration can be determined. The two main groups are passively ventilated instruments, which are mainly installed on aircrafts (e.g. Lance et al., 2010) and actively ventilated instruments, which are mainly used for ground based or tower based measurements (e.g. Burkard et al., 2002; Eugster et al., 2006). In-situ measurements are very challenging due to various difficulties recently discussed for aircraft devices by Lance et al. (2010) and Baumgardner et al. (2011) and for the FSSP in general by Baumgardner (1983) and Baumgardner et al. (1992).

In this paper, we will focus on the Fog Monitor 100 (DMT FM-100, Droplet Measurement Technologies, Boulder, CO, USA), which is a ground based instrument with an active ventilation. We will present a detailed error analysis of two topics influencing the droplet measurements of this device: droplet sizing precision and particle losses. The question whether Mie scattering could be responsible for special features in measured droplet size distribution, for example causing false bimodal size distributions is a common known problem for optical particle counters (e.g. Jaenicke, 1993; Baumgardner et al., 2010). In a first step, we will therefore evaluate how Mie scattering could influence the droplet size spectra collected with the FM-100 and propose a new procedure to reprocess already measured data. Second, we will evaluate droplet losses during sampling with the FM-100, and in a third step, apply both corrections to cloud droplet spectra collected during the CLACE 2010 (the CLoud and Aerosol Characterization Experiment 2010) campaign, performed at the Jungfraujoch (JFJ) in the Swiss Alps. Based on these campaign data, we will provide recommendations on how to improve the measurement quality in future instrument deployments with the FM-100. This is to the best of our knowledge the first work not only mentioning the errors but also proposing a suitable correction procedure, which can be applied to the data after sampling.

The paper is structured such that we first present the measurement site as well as the FM-100 and the instruments used for validation (Sect. 2) which is followed by a methodology section (Sect. 3), focusing on the proposed sizing and particle loss corrections as well as the implementation of both corrections for the data collected at the JFJ (Sect. 4). Finally, we will end with a discussion of the effects of the proposed corrections and provide recommendations how to improve the measurement quality in future instrument set-ups.

\section{Instrumentation and site}

The study to validate and compare the FM-100 with other instruments was performed in the frame of CLACE 2010, which took place at the Jungfraujoch $\left(\mathrm{JFJ}, 46^{\circ} 32^{\prime} \mathrm{N}, 7^{\circ} 59^{\prime} \mathrm{E}\right)$ situated in the Bernese Alps at 3580 ma.s.l., Switzerland (Fig. 1). Several intensive cloud characterization experiments have been conducted there for many years at different times of the year (e.g. Mertes et al., 2007; Verheggen et al., 2007; Cozic et al., 2008; Targino et al., 2009; Kamphus et al., 2010; Zieger et al., 2012). The aerosol measurements performed at the JFJ are part of the Global Atmosphere Watch (GAW) program of the World Meteorological Organization since 1995 (Collaud Coen et al., 2007). Long term studies have been conducted at the site, which indicated that the station is in clouds approximately $40 \%$ of the time throughout the year (Baltensperger et al., 1998). CLACE 2010 took place in June-August 2010 (temperature range: -11 to $11^{\circ} \mathrm{C}$ ) and its main aims were to obtain an in-depth chemical, optical and physical characterization of the aerosols at the JFJ as well as to investigate the interaction of aerosol particles with cloud droplets for improving the understanding of the aerosol direct and indirect effects.

\subsection{FM-100: fog droplet size spectrometer}

The commercial FM-100 fog monitor is a forward scattering spectrometer probe placed in a wind tunnel with active ventilation (Eugster et al., 2006). The instrument measures the number size distribution of cloud particles at high time resolution in the size range between 1.5 and $50 \mu \mathrm{m}$ with a resolution of 10,20,30 or 40 channels which can be selected 


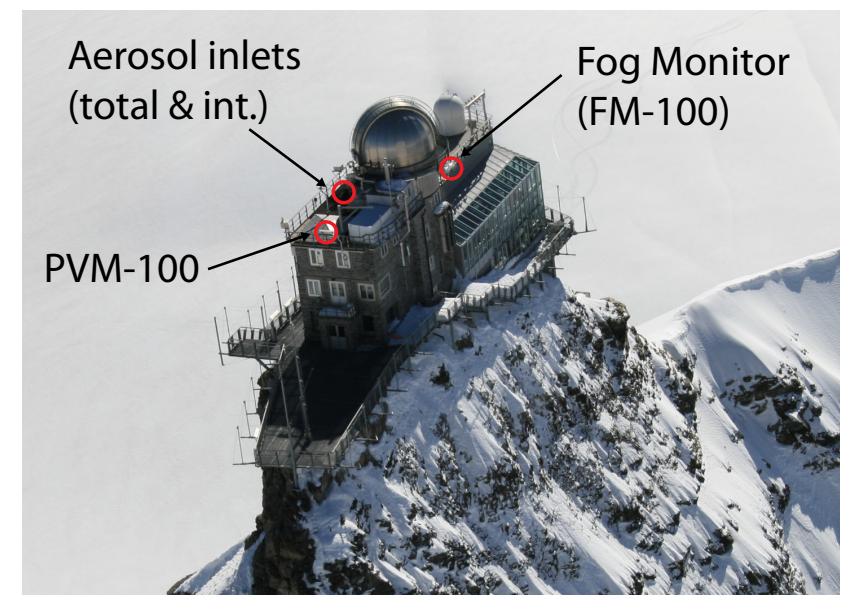

Fig. 1. Position of the Fog monitor (FM-100), Particulate Volume Monitor (PVM-100) and aerosol inlets at the Sphinx platform at the Jungfraujoch (3580 ma.s.l.) during CLACE 2010 (photo courtesy of Boris Schneider, www.metair.ch).

by the user. Channel thresholds and diameters are provided by the manufacturer for 10,20,30 and 40 channels, but can be defined by the user as well. Simultaneously, the temperature as well as the sampled air volume is measured. A sketch of the working principle of the FM-100 is shown in Fig. 2. A pump pulls ambient air through the wind tunnel of the instrument. First, the droplets reach the sizing region, where they pass a laser beam (wavelength $\lambda=658 \mathrm{~nm}$ ). The light which is scattered forward within approximately $3^{\circ}$ to $12^{\circ}$ from the beam direction is collected and directed to an optical splitter and then to a pair of photodetectors. These collectors translate the scattered radiance into a voltage pulse. Under the assumption that there are no saturation effects, the pulse height is proportional to the scattered light intensity. For correct sizing one needs to assure that the detected particle was inside the depth of field (DOF) of the instrument, which is the uniform power region of the laser. To qualify a particle for sizing (meaning that the voltage from the sizer is saved for further processing) the two photodetectors are needed. The scattered light is split by the prism, such that one third is directed to the sizer and two thirds to the qualifier. The qualifier only records radiance that passed the optical mask in front of the detector. If the scattering particle was inside the DOF, the scattered signal of the qualifier exceeds the scattering signal of the sizer. For qualified particles the sizer voltage is directly proportional to the scattered radiance into the solid angle with an inner opening angle of $3^{\circ}$ to $4^{\circ}$ and an outer opening angle of around $12.0^{\circ}$ to $12.6^{\circ}$ (see Fig. 2). The scattered radiance is described by the scattering cross section, which can be calculated using Mie theory (Mie, 1908). The exact values of the scattering angles needed for the Mie calculations differs among instruments. Additionally, they depend on where exactly the particle passes the laser beam (Lance et al., 2010). They need to be derived from glass bead cal-
Table 1. Technical specifications of the FM-100 taken from Droplet Measurement Technologies (2011).

\begin{tabular}{ll}
\hline Fog Monitor FM-100 & \\
\hline Laser wavelength $\lambda$ & $658 \mathrm{~nm}$ \\
Temperature range & $>0{ }^{\circ} \mathrm{C}$ \\
Sampling frequency & $0.1-10 \mathrm{~Hz}$ \\
Inlet diameter $\left(d_{i}\right)$ & $6.6 \mathrm{~cm}$ \\
Contraction part length & $16.1 \mathrm{~cm}$ \\
Wind tunnel length until laser $\left(L_{\mathrm{w}}\right)$ & $10.1 \mathrm{~cm}$ \\
Wind tunnel diameter $\left(d_{o}\right)$ & $3.8 \mathrm{~cm}$ \\
Sampling flow rate (TAS) & around $15 \mathrm{~m} \mathrm{~s}^{-1}$ \\
Light collection angles $^{\mathrm{c}}$ & from $3-4^{\circ}$ to $12-12.6^{\circ}$ \\
\hline
\end{tabular}

a Depending on data retrieval software. Technical maximum observed during our field deployment is $\approx 12.5 \mathrm{~Hz}$ with old instruments and $\approx 14.5 \mathrm{~Hz}$ with newer ones. $\mathrm{b}$ Depending on external pump rate. The sampling flow rate corresponds to the traveling velocity of the droplets.

${ }^{c}$ Light collection angles differ for different instruments.

ibrations followed by Mie calculations to find the solid angle that fits best to the calibration results (D. Baumgardner, Centro de Ciencias de la Atmósfera, Universidad Nacional Autónoma de Mexico, Mexico City, Mexico, personal communication, 2010). They are therefore one of the sources of uncertainty of the FM-100 that will be addressed in this paper. For further details on the electronic part of the FM-100, we refer to Droplet Measurement Technologies (2011).

Behind the sizing region there is a pitot tube measuring the air speed in the tunnel. The air speed (which is the traveling velocity of the droplets) is needed in order to determine the sample volume to infer number concentrations and liquid water content per volume from the measured droplet numbers. Technical specifications are summarized in Table 1 .

A series of parameters can be derived from the measured droplet number size distribution such as total droplet number concentration $\left(N_{\mathrm{FM}}\right)$, and total liquid water content $\left(\mathrm{LWC}_{\mathrm{FM}}\right)$. In this work we will use $N_{\mathrm{FM}}\left(\mathrm{cm}^{-3}\right)$ which is defined as

$N_{\mathrm{FM}}=\sum_{i=1}^{i_{\max }} n_{i}$

and the $\mathrm{LWC}_{\mathrm{FM}}$ (in $\mathrm{mg} \mathrm{m}^{-3}$ ) which is calculated based on the assumption that the droplets are spherical:

$\mathrm{LWC}_{\mathrm{FM}}=\sum_{i=1}^{i_{\max }} \frac{1}{6} \pi D_{i}^{3} n_{i} \rho_{\mathrm{H}_{2} \mathrm{O}}$,

where $i_{\max }$ is the number of channels used, $\rho_{\mathrm{H}_{2} \mathrm{O}}$ is the density of water in $\mathrm{kg} \mathrm{m}^{-3}, D_{i}$ the geometric mean diameter of each channel in $\mu \mathrm{m}$, and $n_{i}$ the droplet number concentration per channel in $\mathrm{cm}^{-3}$ as derived from the sizer signal.

The FM-100 has been used in several ground based studies so far especially as part of an eddy covariance system to quantify fog water deposition fluxes in tropical mountain 
cloud forests (e.g. Eugster et al., 2006; Holwerda et al., 2006; Beiderwieden, 2007; Beiderwieden et al., 2008; Schmid et al., 2010), in temperate ecosystems (Burkard et al., 2002; Thalmann, 2002; Burkard, 2003), and deposition fluxes in rather arid areas (Westbeld et al., 2009). It has also been used as a single instrument for microphysical studies of fog (Gonser et al., 2011; Liu et al., 2011) and compared to other devices (Holwerda et al., 2006; Schmid et al., 2010; Frumau et al., 2011). Most of the presented work used the channel configuration defined by the manufacturer in order to translate the voltage to a droplet size; while Niu et al. (2010) used the 20 channel configuration, which is the one that is used by the manufacturer to calibrate the instrument, some of the authors (Burkard et al., 2002; Eugster et al., 2006; Beiderwieden, 2007; Beiderwieden et al., 2008; Westbeld et al., 2009; Frumau et al., 2011) used the 40 channel configuration in order to obtain a better resolved size distribution. A different approach was taken by Gonser et al. (2011) - which is one of the most recent publications - who defined their own 23 channel sizes and widths by using Mie curves prior to sampling. Such a procedure has already been suggested earlier for the FSSP (Pinnick et al., 1981; Dye and Baumgardner, 1984). Nevertheless, this has not been the standard procedure for the FM-100 so far. Here, we will propose a similar procedure that can be applied after sampling.

The FM-100 was installed on the NW corner of the upper terrace of the observation platform (Sphinx station, Fig. 1) and the inlet was turned into the mean wind direction $\left(323^{\circ}\right)$ as was expected for June/July conditions based on a dataset from MeteoSwiss from 1990 to 2009. For the second part of the campaign, the device was inclined and a horizontal angle of $293^{\circ}$ and a vertical angle of $-25^{\circ}$ were chosen in order to account for the pronounced upwind aspiration at this site.

\subsection{Instrumentation used for validation of the FM-100}

\subsubsection{Aerosol inlets}

For the collection of aerosols an interstitial and a total inlet were installed at a fairly undisturbed place on the roof of the observation laboratory at the Jungfraujoch (Fig. 1). The interstitial inlet was installed for collecting particles smaller than $2 \mu \mathrm{m}$. It uses an aerodynamic size discriminator without heating (Henning et al., 2002). Thus, all non-activated particles pass this inlet. The total inlet samples all particles smaller than $40 \mu \mathrm{m}$ at wind speeds up to $20 \mathrm{~m} \mathrm{~s}^{-1}$ (Weingartner et al., 1999). Hence, the heated total inlet samples cloud droplets and non-activated (interstitial) aerosols. The condensed water on the cloud droplets and aerosols is evaporated by heating up the total inlet to $+20^{\circ} \mathrm{C}$ (Henning et al., 2002).

\subsubsection{PVM-100: Particulate Volume Monitor}

The Particulate Volume Monitor (PVM-100, Gerber Scientific Instruments Inc.) is an open path optical instrument that

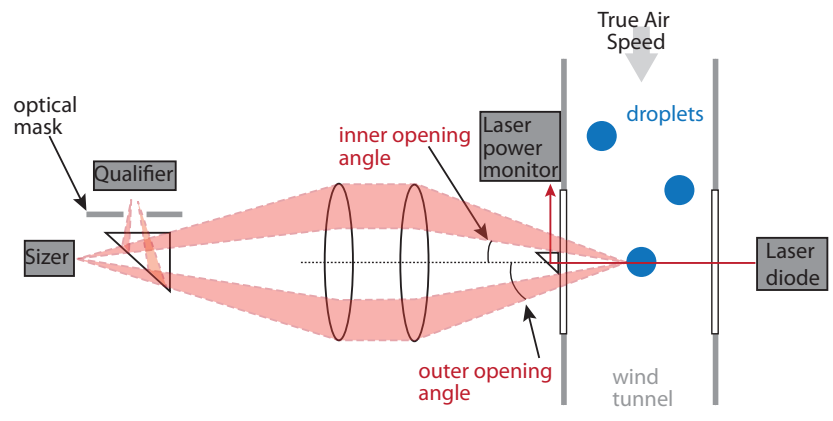

Fig. 2. Schematic view of the theory of operation of the FM-100 (modified from Droplet Measurement Technologies, 2011). Cloud droplets (blue dots) are pulled through the wind tunnel at constant speed (True Air Speed=TAS) and pass the laser beam. The scattered light (red) from the particle is directed through the optical system and then detected by the qualifier and sizer. The inner and outer opening angle depend on the individual instrument and the position where exactly the droplet passed the laser beam.

measures the light scattered in the forward direction of all abundant particles in the sample volume. A detailed description can be found in Gerber (1991) and Arends et al. (1994). The PVM-100 was installed on the eastern side of the sphinx roof (Fig. 1). Based a PVM-100 intercomparison during an earlier campaigns, we do not expect any considerable differences in the LWC measurements due to the different locations at the building. The PVM-100 needs calibration in order to translate the scattering signal into an LWC. The instrument was periodically calibrated with a calibration disk provided by the manufacturer. Particles with a diameter of 3 to $45 \mu \mathrm{m}$ are taken into account and the calibration is valid for an LWC range from 0.002 to $10 \mathrm{~g} \mathrm{~m}^{-3}$ and a measurement accuracy of $15 \%$ (Allan et al., 2008). The LWC measured by the PVM is hereafter referred to as $\mathrm{LWC}_{\mathrm{PVM}}$.

\subsubsection{Dew point hygrometer}

The PVM-100 as well as the FM-100 both measure the LWC of a cloud using a similar optical method. In order to get another estimate of the LWC that is independent of potential problems associated with light scattering techniques, we computed the condensed water content (CWC) of the cloud with a simple thermodynamic method based on the following assumptions: First, we assume that the cloud is liquid (no ice crystals). So the CWC is equivalent to the LWC of the cloud. Second, we assume that the water vapor pressure can be described by the ideal gas law, which is fulfilled for atmospheric conditions. Third, the cloud is saturated (= relative humidity $100 \%$ ). The first criterion is fulfilled in warm fog events, which we select via a temperature threshold of $0^{\circ} \mathrm{C}$ for our analysis. By taking the ambient temperature measured by the SwissMetNet station (operated by MeteoSwiss) the corresponding saturation vapor pressure for water can be calculated during cloud events. Using the ideal gas law 
equation and under the assumption of $100 \% \mathrm{RH}$ the water content in the vapor phase can be deduced (VWC). Simultaneously, we measured the dew point temperature with a high accuracy dew point hygrometer (Dewmaster, Edgetech West Wareham, Massachusetts, USA; precision $\pm 0.1^{\circ} \mathrm{C}$ ) after the ambient air has passed a heated inlet. Thus, the air reaching the dew point hygrometer contains all the water present in the ambient air (i.e. the evaporated droplets and gas phase). Hence, by calculating the equilibrium pressure at the dew point we can deduce the total amount of water (TWC) of the ambient air parcel using the ideal gas law. The CWC of the ambient air parcel is then: $\mathrm{CWC}=\mathrm{TWC}-\mathrm{VWC}$.

\subsubsection{Scanning Mobility Particle Sizer (SMPS)}

Behind both inlets Scanning Mobility Particle Sizer (SMPS) systems were used to measure the number size distributions of the total and the interstitial aerosol between 17 and $900 \mathrm{~nm}$ (dry) diameter (Verheggen et al., 2007). The SMPS system behind the total inlet consisted of a Differential Mobility Analyzer (DMA, TSI 3071) and a condensation particle counter (CPC, TSI 3022A). The other SMPS system behind the interstitial inlet consisted of a DMA (TSI 3071) and a CPC (TSI 3775). During cloud-free conditions the response of the total and interstitial inlets should be identical. The interstitial size spectrum was corrected towards the total spectrum by a size-dependent correction factor for the small systematic difference in concentration between the two inlets (interstitial up to $25 \%$ lower than total for particles smaller than $30 \mathrm{~nm}$, concentrations within $5 \%$ for larger particles), as particle losses were expected to be higher in the interstitial inlet, due to a longer residence time in the sampling line. The integration of the respective distribution gives the total number concentration of the total $\left(N_{\text {tot }}\right)$ or non-activated aerosols $\left(N_{\text {int }}\right)$. The difference $\left(N_{\text {tot-int }}\right)$ is the number concentration of the cloud droplets and can be compared to the number concentration of cloud droplets measured by the FM-100. The methodological accuracy of the SMPS number size distributions was $\pm 10 \%$ in concentration for particle diameters larger than $20 \mathrm{~nm}$ and $\pm 20 \%$ for smaller particles, respectively. Based on the cross-comparison of the two SMPS systems, the precision in $N_{\text {tot-int }}\left(=N_{\mathrm{cr}}\right.$ for number concentration of cloud residuals later on) was estimated to be $\pm 50 \mathrm{~cm}^{-3}$.

\subsubsection{Ultrasonic anemometer}

The wind field around the FM-100 has an important influence on the data quality of the FM-100. Therefore, a HS ultrasonic anemometer (Gill Ltd., Solent, UK) was installed at $1.7 \mathrm{~m}$ away from the FM-100. The ultrasonic anemometer was run together with the FM-100 using an in-house data acquisition software (Eugster and Plüss, 2010) recording data at $12.5 \mathrm{~Hz}$. Thus, microphysical processes can be studied at a high temporal resolution.

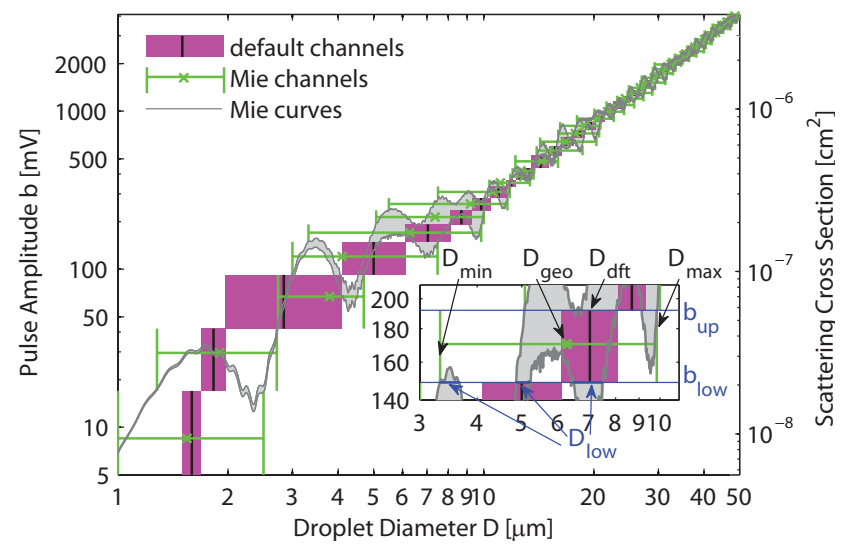

Fig. 3. Mie curves for a laser wavelength of $\lambda=658 \mathrm{~nm}$ as well as the default channels from the manufacturer (pink) and the Mie channels (green). The inset shows for channel 5 how the minimum diameter $D_{\min }$ and maximum diameter $D_{\max }$ are deduced from the intersections of the Mie curves with $b_{\text {low }}\left(D_{\text {low }}\right)$ and $b_{\text {up }}\left(D_{\text {up }}\right)$. Additionally, the geometric mean diameter $D_{\text {geo }}$ and the diameter of the default channels are depicted $\left(D_{\mathrm{dft}}\right)$.

\section{Methods: sizing and counting corrections for the FM-100}

\subsection{Corrections for the size detections of the FM-100 due to Mie theory}

In order to deduce the size of each droplet from the measured signal, the scattering cross section (see Fig. 3; Mie curves are shown in gray) needs to be inverted. As this curve is highly non-monotonic, this is not a trivial task. This is an inherent problem of all types of optical particle counters as seen by many previous studies (e.g. Pinnick et al., 1981; Dye and Baumgardner, 1984; Rosenfeld et al., 2012). The manufacturer solved this problem as follows: the Mie curves were smoothed (by applying a running average) to an extent that yielded a monotonic function and then attributed four different channel ranges to it: 10, 20, 30 and 40 (D. Baumgardner, personal communication, 2010). So the user can decide whether to use $10,20,30$ or 40 channels. This procedure does not account for sizing ambiguities, i.e. a particle with a diameter of around $3 \mu \mathrm{m}$ has a similar scattering cross section as a particle with a diameter of around $8 \mu \mathrm{m}$. With this default configuration, the signal of both the 3 and the $8 \mu \mathrm{m}$ particle are interpreted as a particle of $5 \mu \mathrm{m}$. In Fig. 3, the pink boxes show the 40 channels that have been deduced in the described way for the used FM-100. The default channels varied between $0.19 \mu \mathrm{m}$ (first channel) and $2.13 \mu \mathrm{m}$ in channel width with a mean value of $1.21 \mu \mathrm{m}$ (see Table 2 for more details). We will refer to these channels later on using the term default channels (with geometric mean diameters $D_{\mathrm{dft}}$ ), and the LWC derived from this configuration we will be referred to as $\mathrm{LWC}_{\mathrm{dft}}$. 
Table 2. Channel range of the default (ranging from $D_{\mathrm{dft} \text {,min }}$ to $D_{\mathrm{dft} \text {,max }}$ with a geometric mean diameter $D_{\mathrm{dft}}$ ) and the new Mie channels (ranging from $D_{\min }$ to $D_{\max }$ with a geometric mean diameter $D_{\text {geo }}$ ). Values are given in units of $\mu \mathrm{m}$.

\begin{tabular}{|c|c|c|c|c|c|c|}
\hline & \multicolumn{3}{|c|}{ Default channels } & \multicolumn{3}{|c|}{ Mie channels } \\
\hline & $D_{\mathrm{dft}, \min }$ & $D_{\mathrm{dft}, \max }$ & $D_{\mathrm{dft}}$ & $D_{\min }$ & $D_{\max }$ & $D_{\text {geo }}$ \\
\hline 1 & 1.50 & 1.69 & 1.59 & 1 & 2.50 & 1.54 \\
\hline 2 & 1.69 & 1.97 & 1.82 & 1.28 & 2.72 & 1.90 \\
\hline 3 & 1.97 & 4.10 & 2.84 & 2.74 & 4.70 & 3.79 \\
\hline 4 & 4.10 & 6.10 & 5.00 & 3.00 & 7.48 & 4.11 \\
\hline 5 & 6.10 & 8.11 & 7.03 & 3.32 & 9.84 & 6.27 \\
\hline 6 & 8.11 & 9.30 & 8.68 & 5.08 & 10 & 7.36 \\
\hline 7 & 9.30 & 10.42 & 9.84 & 5.50 & 11.60 & 9.19 \\
\hline 8 & 10.42 & 11.54 & 10.97 & 7.50 & 11.78 & 10.59 \\
\hline 9 & 11.54 & 12.24 & 11.88 & 10.36 & 13.38 & 11.11 \\
\hline 10 & 12.24 & 12.90 & 12.57 & 11.82 & 13.68 & 12.86 \\
\hline 11 & 12.90 & 13.54 & 13.22 & 12 & 13.74 & 12.64 \\
\hline 12 & 13.54 & 15.07 & 14.28 & 12.20 & 15.96 & 14.43 \\
\hline 13 & 15.07 & 16.29 & 15.67 & 13.96 & 18.60 & 15.06 \\
\hline 14 & 16.29 & 17.58 & 16.92 & 14.26 & 20.32 & 16.69 \\
\hline 15 & 17.58 & 18.94 & 18.25 & 15.98 & 20.66 & 17.80 \\
\hline 16 & 18.94 & 20.29 & 19.60 & 16.16 & 20.84 & 18.88 \\
\hline 17 & 20.29 & 21.46 & 20.87 & 17.98 & 22.64 & 20.45 \\
\hline 18 & 21.46 & 22.66 & 22.05 & 20.04 & 24.16 & 21.81 \\
\hline 19 & 22.66 & 24.02 & 23.33 & 21.64 & 25.76 & 23.59 \\
\hline 20 & 24.02 & 25.16 & 24.58 & 23.16 & 27.32 & 24.40 \\
\hline 21 & 25.16 & 26.35 & 25.75 & 24.74 & 28.86 & 25.87 \\
\hline 22 & 26.35 & 27.45 & 26.89 & 24.92 & 29.40 & 26.77 \\
\hline 23 & 27.45 & 28.62 & 28.03 & 26.82 & 31.34 & 28.18 \\
\hline 24 & 28.62 & 29.75 & 29.18 & 27.02 & 31.62 & 29.24 \\
\hline 25 & 29.75 & 30.71 & 30.23 & 28.88 & 32.88 & 30.30 \\
\hline 26 & 30.71 & 31.98 & 31.34 & 29.00 & 33.40 & 31.44 \\
\hline 27 & 31.98 & 33.18 & 32.57 & 29.30 & 34.66 & 32.51 \\
\hline 28 & 33.18 & 34.38 & 33.77 & 32.10 & 36.38 & 34.16 \\
\hline 29 & 34.38 & 35.60 & 34.98 & 33.28 & 38.10 & 35.26 \\
\hline 30 & 35.60 & 36.79 & 36.19 & 34.86 & 39.98 & 36.83 \\
\hline 31 & 36.79 & 38.02 & 37.40 & 36.06 & 40.38 & 37.78 \\
\hline 32 & 38.02 & 39.24 & 38.63 & 37.66 & 41.94 & 39.00 \\
\hline 33 & 39.24 & 40.53 & 39.88 & 37.84 & 42.32 & 40.16 \\
\hline 34 & 40.53 & 41.83 & 41.17 & 39.74 & 43.14 & 41.25 \\
\hline 35 & 41.83 & 43.23 & 42.52 & 40.12 & 45.10 & 43.01 \\
\hline 36 & 43.23 & 44.59 & 43.90 & 41.86 & 47.22 & 43.74 \\
\hline 37 & 44.59 & 45.98 & 45.28 & 42.22 & 47.56 & 45.35 \\
\hline 38 & 45.98 & 47.16 & 46.57 & 43.78 & 49.12 & 46.13 \\
\hline 39 & 47.16 & 48.57 & 47.86 & 45.70 & 49.34 & 47.53 \\
\hline 40 & 48.57 & 50.00 & 49.28 & 46.92 & 49.98 & 48.58 \\
\hline
\end{tabular}

Throughout this text we will use the following terms: each channel is defined by a lower and an upper margin for the pulse amplitude, which we will later on refer to $b_{\text {low }}$ and $b_{\text {up }}$ (see Fig. 3 for details). $b_{\text {up }}-b_{\text {low }}$ will be referred to as "channel height", i.e. with the term "channel width", we refer to the droplet diameter range that is covered by this channel.

In the next section, we suggest two approaches on how to take the Mie curve variations for sizing into account: one by using channels that are wide enough to cover the Mie variations (Sect. 3.1.1) and another to obtain a new size dis- tribution by redistributing the measured counts per channel (Sect. 3.1.2).

\subsubsection{Widening of the size bins of the FM-100 and error calculations}

Redefining channel limits as well a combining channels to remove the ambiguity in sizing has been suggested for different optical particle counters by previous studies (e.g. Pinnick et al., 1981; Dye and Baumgardner, 1984). However, to the extend of our knowledge, none of them proposes overlapping channels (as presented in this section) or the use of a stochastic approach (next section) in order to retrieve the droplet size distribution from the measured signal.

The procedure to derive new channels is as follows: in a first step we made Mie calculations for the optical system using an algorithm further developed from Mätzler (2002) which in turn is based on the work by Bohren and Huffman (1983). The derivation of the scattering cross section as well as detailed calculations can be found in the corresponding literature (e.g., Mie, 1908; Van de Hulst, 1981; Bohren and Huffman, 1983; Liou, 2002). The inner and outer angles of the scattering cone (see Fig. 2) were not clearly determined during manufacturing of the FM-100 (= instrumentation uncertainty) and hence needed to be estimated via glass bead calibrations. Additionally, these angles also depend on where exactly the droplet passes the laser beam (= spatial uncertainty). We therefore did several Mie calculations starting with a cone with an inner opening angle of $3^{\circ}$ and an outer opening angle of $12^{\circ}$. By increasing the angles stepwise by $0.1^{\circ}$ to $4^{\circ}$ for the inner angle and $12.6^{\circ}$ for the outer angle, we obtained a set of Mie curves that represents the scattering cross sections of the droplets including instrumental and spatial uncertainty (see Fig. 3; the maximum and minimum of this Mie curve set are shown in dark gray). We then translated this Mie band into a voltage as it is done in the FM-100 electronics by assuming a linear relationship between scattered light intensity and voltage signal and setting the scattering cross section of a $50 \mu \mathrm{m}$ particle equal to $4096 \mathrm{mV}$ (D. Baumgardner, personal communication, 2010). In a second step, we used the Mie band to reassign new droplet diameters to each of the channels. In the following we will use the values for channel 5 for illustration (inset Fig. 3). As the FM-100 only determines whether a particle was detected in a certain channel while the exact light scattering signal is not recorded, we had to keep the channel boundaries $b_{\text {low }}$ $(149 \mathrm{mV})$ and $b_{\text {up }}(192 \mathrm{mV})$ as they were configured during the measurements. Hence, for each channel we searched the lowest droplet diameter that still yielded a voltage signal within the height of the respective channel. $b_{\text {low }}$ intersects the Mie band at different diameters $D_{\text {low }}(=3.32$ to $3.66 \mu \mathrm{m}$ and 4.86 to $5.22 \mu \mathrm{m}$ and 6.48 to $7.50 \mu \mathrm{m}$, see inset Fig. 3 for details). The minimum of the set of $D_{\text {low }}$ is the minimum diameter of this channel $\left(D_{\min }=\min \left\{D_{\text {low }}\right\}=3.32 \mu \mathrm{m}\right)$. Similarly, the maximum diameter $D_{\max }$ corresponding to this 

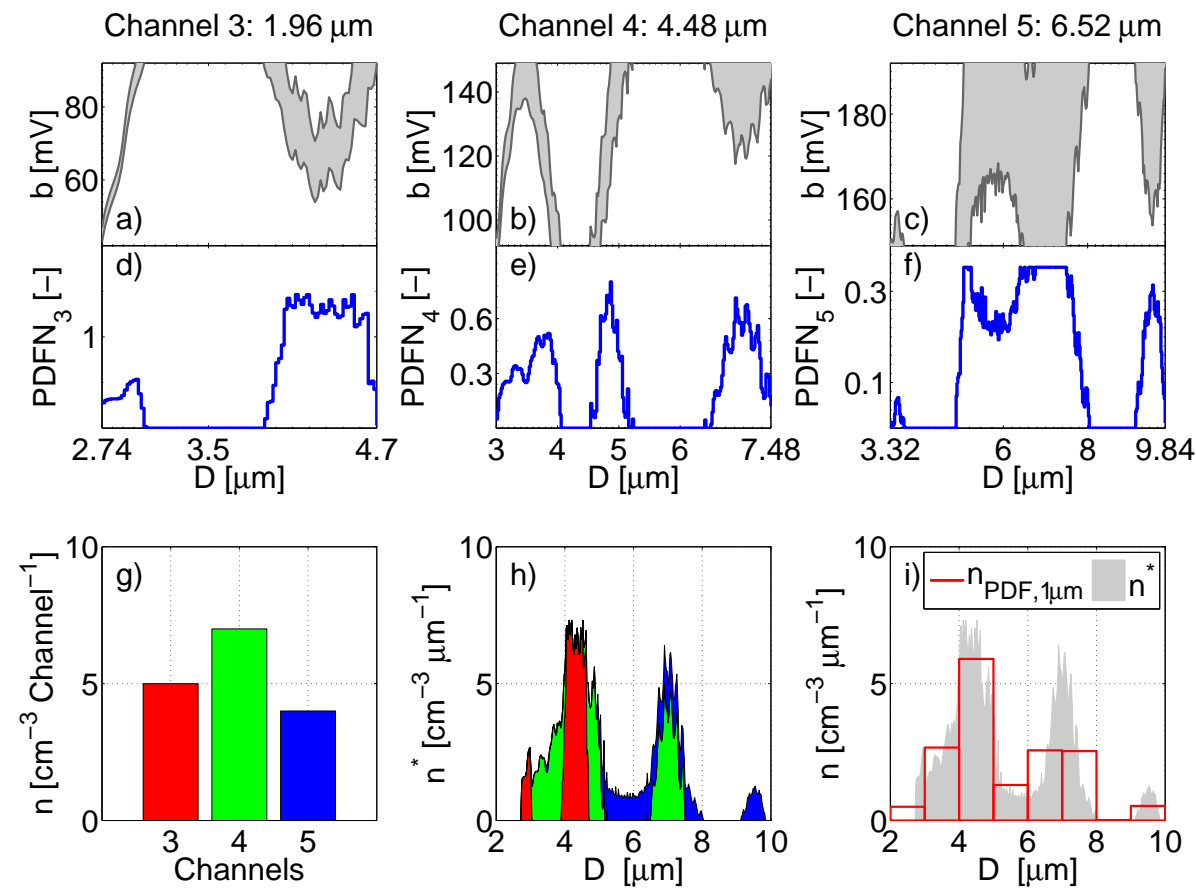

Fig. 4. (a) to (c) Pulse amplitude $b$ versus diameter (shown in the range of $D_{\min }$ to $D_{\max }$ and $b_{\text {low }}$ and $b_{\text {up }}$ ) for the channels 3 , 4 , and 5 . (d) to (f) Normalized probability density function $\mathrm{PDFN}_{i}$ for the same channels as in (a) to (c). (h) Discrete droplet size distribution $n^{*}$ with a resolution of $0.02 \mu \mathrm{m}$ if the PDFN approach is used with the $\mathrm{PDFN}_{i}$ functions from (d) to (f) and the number size distribution from (g). (i) Discrete droplet size distribution $n^{*}$ - gray area, same as in (h) - and the re-binned size distribution $n_{\mathrm{PDF}, 1 \mu \mathrm{m}}$ with the bin size of $\Delta D=1 \mu \mathrm{m}$ (red bars).

channel was derived by taking the maximum of the set of $D_{\text {up }}\left(D_{\max }=\max \left\{D_{\text {up }}\right\}=9.84 \mu \mathrm{m}\right)$. From the geometric mean $\left(D_{\text {geo }}=6.27 \mu \mathrm{m}\right)$ of the minimum and the maximum, we then obtained the new droplet diameter to be assigned to this channel. We then repeated this procedure for all other channels. By doing this we obtained three monotonic curves that can be easily inverted and used to evaluate the signal: the geometric mean curve, as a mean estimate for the size distribution, the minimum and the maximum as a lower and upper estimate for the size distribution, respectively. In that way the channels (later on referred to as Mie channels) became wider and therefore overlap, with channel width varying from $1.44 \mu \mathrm{m}$ to $6.52 \mu \mathrm{m}$ with a mean channel width of $4.21 \mu \mathrm{m}$ (see Table 2 for more details). However, the differences of the geometric means $\left(D_{\mathrm{dft}}\right.$, black bar in the pink boxes for the default channels, and $D_{\text {geo }}$ green crosses for the Mie channels in Fig. 3) between the two configurations was always smaller than $1.32 \mu \mathrm{m}$ (see Table 2). Out of the maximum 40 channels, 21 channels were smaller with the default channel configuration than the Mie channel configuration and 19 channels were wider.

This way of translating the voltage signal has the advantage that it also provides the uncertainty of the droplet sizes associated with the Mie scattering, but at the expense of clear channel separation. The LWC derived using the mean channels will hereafter be referred to as $\mathrm{LWC}_{\text {geo }}$, the one us- ing the maximum curve as $\mathrm{LWC}_{\max }$ and the one using the minimum curve as $\mathrm{LWC}_{\min }$.

\subsubsection{Retrieving a new droplet size distribution using probability density functions}

With the method above it is possible to retrieve an appropriate maximal error assumption for the LWC. However, the FM-100 was mainly designed for measuring droplet size distributions. The question arises on how to retrieve a size distribution for channels which overlap. In this section we therefore present a new method on how size distributions that account for Mie scattering can be deduced from measured distributions. We consider this new approach to be the best way of dealing with the Mie uncertainties with respect to overlapping channels.

Due to the channel overlap an adequate size distribution could be achieved by redistributing the number counts per channel over an adequate channel width. For this purpose we had a closer look at the channels, which were defined in the previous section. The procedure will be explained in the following using channel 5 as an example (Fig. $4 \mathrm{c}$ and f). Channel 5 ranged from $D_{\min }=3.32 \mu \mathrm{m}$ to $D_{\max }=9.84 \mu \mathrm{m}$ (see Fig. 3 inset). The Mie band of channel 5 was not uniformly distributed along the channel width (Fig. 4c), e.g. droplets between $3.64 \mu \mathrm{m}$ and $4.86 \mu \mathrm{m}$ as well as between $8.04 \mu \mathrm{m}$ 
and $9.12 \mu \mathrm{m}$ did not produce a scattering signal that fell into this channel height. On the other hand, droplets between $6.76 \mu \mathrm{m}$ and $7.48 \mu \mathrm{m}$ covered the entire channel height with their scattering signal. So if a scattering signal between 149 and $192 \mathrm{mV}$ is detected, it is more likely that it came from a droplet that has a size between $6.76 \mu \mathrm{m}$ and $7.48 \mu \mathrm{m}$ than $3.64 \mu \mathrm{m}$ and $4.86 \mu \mathrm{m}$. To account for this, we calculated a probability density function based on the Mie band that represents the contribution of each droplet size to the scattering signal within the channel. It includes the assumption that each scattering cross section within the Mie band is equally probable, which we consider to be a reasonable first approximation. For the redistribution, the measured number concentration was multiplied with the normalized probability density function leading to a stochastic assumption of the droplets that could have produced the according scattering signal. The procedure was as follows: First, discrete probability density functions $\left(\operatorname{PDF}_{i}(D)\right)$ for each channel $(i)$ were deduced from the Mie band. Each channel was divided in $\Delta D_{\mathrm{R}}=0.02 \mu \mathrm{m}$ intervals from $D_{\min }$ to $D_{\max }$. For each diameter $D$, the percentage of the Mie band relative to the pulse amplitude height $\left(b_{\text {up }}-b_{\text {low }}\right)$ of the channel was calculated:

$\operatorname{PDF}_{i}(D)$ with $D \in\left[D_{\min }(i), D_{\max }(i)\right]$.

This resulted in a curve from $D_{\min }$ to $D_{\max }$, which was 1 if the pulse covered the entire channel height. Second, this discrete probability density function was normalized (Fig. 4c to f) such that

$$
\begin{aligned}
& \Delta D_{\mathrm{R}} \times \sum_{D=D \text { min }}^{D \text { max }} \operatorname{PDFN}_{i}(D)=1 ; \\
& \operatorname{PDFN}_{i}(D)=\frac{\operatorname{PDF}_{i}(D)}{\Delta D_{\mathrm{R}} \times \sum_{D=D \text { min }}^{D \text { max }} \operatorname{PDF}_{i}(D)}
\end{aligned}
$$$$
\text { with } D \in\left[D_{\min }(i), D_{\max }(i)\right] \text {. }
$$

Third, the amount of droplets measured per channel $N_{i}$ was redistributed from $D_{\min }$ to $D_{\max }$ based on the normalized probability density function. This was done for every channel leading to a discrete droplet number distribution $n^{*}$ with a resolution of $\Delta D_{\mathrm{R}}=0.02 \mu \mathrm{m}$ :

$n^{*}(D)=\sum_{i=1}^{i_{\max }} N_{i} \times \operatorname{PDFN}_{i}(D)$.

In order to account for uncertainties (such as the equally probable Mie band or slightly different opening angles), a new droplet size distribution based on bins with the same size $\Delta D$ should be retrieved ( $n_{\mathrm{PDF}, a \mu \mathrm{m}}$ refers to channels with bin size $\Delta D=a \mu \mathrm{m}$ ). The liquid water content based on this method will be referred to as $\mathrm{LWC}_{\mathrm{PDF}, a \mu \mathrm{m}}$. This procedure was applied to one minute mean values of the collected cloud droplet spectra from CLACE 2010.

\subsection{Particle losses}

While measuring droplets, one is facing the problem that cloud droplets are rather heavy and therefore are influenced by their inertia and gravity. Hence, depending on their size and volume, they do not necessarily follow exactly the same trajectories as gas molecules would. This means that there is a potential for particle losses during sampling from ambient air (sampling efficiency, $\eta_{\mathrm{smp}}(D)$ ) and during transport through the system (transport efficiency, $\eta_{\mathrm{tsp}}(D)$ ). One way of assessing this issue is to simulate particle transport through a system using computational fluid dynamics (CFD). Another approach is to use experimentally and theoretically derived formulas for different loss mechanisms within the different tube sections in order to calculate the overall efficiency. As CFD calculations are very time-consuming, we will therefore use the second approach for particle losses in the FM-100 as a first estimate.

In general, the efficiency $\eta$ is the fraction of the number concentration of droplets downstream of the loss mechanism and the droplet number concentration upstream. The fraction of particle losses is then $1-\eta$. The product of the sampling and the transport efficiency is the inlet efficiency $\eta_{\text {tot }}$, which describes the performance of the sampling device (von der Weiden et al., 2009). Sometimes the efficiencies are named differently, (e.g. in Brockmann, 2011). Nevertheless, throughout this text we will adhere to terms used by von der Weiden et al. (2009):

$\eta_{\mathrm{tot}}(D)=\eta_{\mathrm{smp}}(D) \times \eta_{\mathrm{tsp}}(D)$.

In general, different particle loss mechanisms contribute to the losses in the two parts of the measurement system. An overview of the different mechanisms was given, e.g. by von der Weiden et al. (2009). Here, we will only discuss the mechanisms which are relevant for the FM-100 (see Fig. 5 for illustration): aspiration losses $\eta_{\text {asp }}$, transmission losses $\eta_{\text {trm }}$, sedimentation losses $\eta_{\text {grav }}$ inside the FM-100, losses due to eddy formation $\eta_{\text {turb }}$ inside the FM-100, and inertial losses in the contraction $\eta_{\text {cont }}$. In the following we shortly introduce sampling and transport losses and refer to the Appendix A for a detailed presentation of the used formulas.

\subsubsection{Sampling losses}

During ideal sampling conditions, the sampling is isoaxial and isokinetic (Brockmann, 2011). Isoaxial means that the sampling inlet has no inclination with respect to the surrounding wind direction. The term isokinetic sampling indicates that the sampling speed $(U)$ is equal to the surrounding wind speed $\left(U_{0}\right)$. If the sampling speed is smaller than the ambient wind speed, the term sub-kinetic sampling is used, while for $U>U_{0}$ the term super-kinetic sampling is used. It will be used in the following for the turbulent as well as for the laminar regime as it has been done by others before (von der Weiden et al., 2009; Brockmann, 2011). 


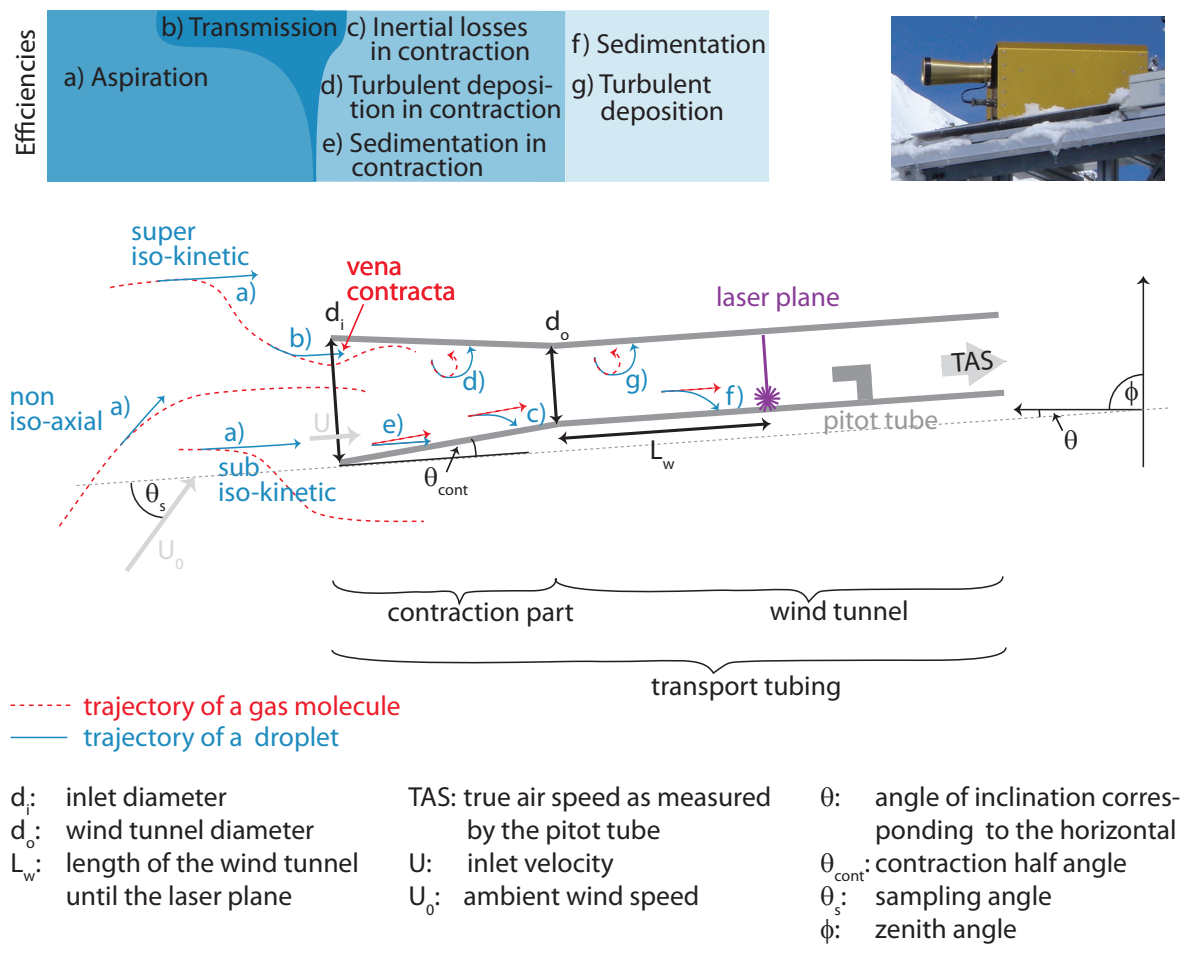

Fig. 5. Illustration of the different particle loss mechanisms - (a) to (g) - as described in Sect. 3.2 for the FM-100 (the small photograph shows the FM-100 at Jungfraujoch). Values for the FM-100 geometry are given in Table 1. Detailed description of the formulas of the particle loss mechanisms are given in Appendix A.

Both regimes need to be taken into account when setting up an inlet system and where and how to position the instrument (Brockmann, 2011). One way of addressing the isoaxial sampling is to put the instrument onto a turntable and letting it continually turn into the main wind direction as done by Vong (1995), Kowalski et al. (1997), Kowalski (1999), Wrzesinsky (2000), Burkard et al. (2002), Thalmann (2002), Burkard (2003), Eugster et al. (2006), and Holwerda et al. (2006). Nevertheless, these procedures do not assure isokinetic sampling conditions.

Westbeld et al. (2009) and Liu et al. (2011) also installed the FM-100 in a fixed position for the entire measurement campaign. They established a quality criterion, by only accepting data as good data if the horizontal wind direction does not differ by a certain degree from the actual inlet orientation. Westbeld et al. (2009) used $\pm 30^{\circ}$ of the hourly mean wind direction and Liu et al. (2011) used $\pm 7^{\circ}$ for this criterion. However, a clear justification why they chose these angles was not given. Instead of excluding any data immediately, we suggest to calculate the sampling efficiency for the FM-100 in order to estimate the losses and correct for those. The sampling efficiency $\eta_{\text {smp }}$ is defined as the fraction of particles of interest (for the FM-100: the droplets), which reach the sampling probe from the surrounding air and successfully penetrate into the transport tubing. In general, the sampling efficiency itself consists of two different contributions:

$\eta_{\text {smp }}(D)=\eta_{\text {asp }}(D) \times \eta_{\text {trm }}(D)$.

The aspiration efficiency $\eta_{\text {asp }}$ is the ratio of the number concentration of particles that enter the sampling probe cross section to the number concentration of particles in the ambient air (von der Weiden et al., 2009; Brockmann, 2011).

For the FM-100 we calculate the aspiration efficiency for the three different velocity regimes: (1) calm air (surrounding wind velocity $U_{0}<0.5 \mathrm{~m} \mathrm{~s}^{-1}$ ), (2) slow moving air $\left(0.5 \mathrm{~m} \mathrm{~s}^{-1} \leq U_{0} \leq 2.18 \mathrm{~m} \mathrm{~s}^{-1}\right.$, which corresponds to a velocity ratio $R_{\mathrm{v}}=U_{0} / U$ of up to 0.5 ; with inlet velocity $U$ ), and (3) moving air (velocity ratio $R_{\mathrm{v}}=0.5$ to 2 ) and different angle regimes. Details on the used formulas are given in the Appendix A1.

The transmission efficiency $\left(\eta_{\text {trm }}\right)$ is the ratio of particle concentration exiting the inlet to the particle concentration just past the inlet face (formulas are given in the Appendix A2).

\subsubsection{Transport losses $\eta_{\text {tsp }}(D)$}

In contrast to the sampling losses, the transport losses do not depend on the flow conditions outside the sampling device. The transport losses are described by the transport efficiency of the tubing system which is the ratio of the number concentration of particles leaving the tubing system divided by the 
particles entering the tubing system. As different loss mechanisms happen in the transport system, the overall transport efficiency of a tubing system is the product of the all particle loss mechanisms for all tubing sections (Brockmann, 2011):

$\eta_{\mathrm{tsp}}(D)=\prod_{\text {sec }}\left[\prod_{\text {mech }} \eta_{\text {sec,mech }}(D)\right]$,

where $\eta_{\text {sec,mech }}$ are the different loss mechanisms per section. In the FM-100 there is a two-part tubing section: the contraction zone of $16 \mathrm{~cm}$ length and the wind tunnel with constant diameter with a length of $10 \mathrm{~cm}$ (see Fig. 5). For both parts we calculated transport losses due to sedimentation $\eta_{\text {grav }}$ and turbulent inertial deposition $\eta_{\text {turb }}$ as well as inertial losses in the contraction part $\eta_{\text {cont }}$. Detailed formulas are given in the Appendix A3.

\subsubsection{Application of the corrections for particle losses to the FM-100}

The described efficiencies were calculated numerically from the minimal diameter to the maximal diameter in $0.1 \mu \mathrm{m}$ steps for each channel. Then we took the mean value of all these efficiencies and attributed them to each channel such that we get one efficiency for each channel. For the default channel configuration as well as for the channels based on the density distribution method, we did the efficiency calculation for each channel separately, using the according geometric mean values.

For Stokes numbers smaller than the validity range of the correcting formulas (aspiration, transmission and inertial deposition efficiency in the contraction), we applied the proposed formulas as they yielded efficiencies close to 1 . This would be an appropriate description as we assume that the particles are small enough to follow the same trajectory as gas molecules.

The used formulas are valid for constant gas velocities (Brockmann, 2011). To conform with these assumptions as closely as possible, we calculated the efficiencies for 1-min intervals, with approximately constant wind velocity. As we basically only have anisoaxial sampling, we only used formulas for the anisoaxial regime.

Unfortunately, the proposed equation for the calm flow regime (Eq. A4) is not valid for the second part of the CLACE 2010 period, when the FM-100 was installed with its inlet facing downwards (zenith angle $\phi=115^{\circ}$ ). Though, Grinshpun et al. (1993) only excluded angles larger than $90^{\circ}$ because it was not common to use an inlet facing downwards. However, $\frac{V_{\text {ts }}}{U} \cos \phi$ correctly describes the sedimentation even if the zenith angle is larger than $90^{\circ}$. We therefore apply this formula also for the time the FM-100 faced downwards. With the same argumentation, we extend the formula for sedimentation losses for the downward sampling (Eq. A13). If $\eta_{\text {tot }}$ could not be calculated for all droplet sizes (e.g. due to too high Stokes numbers), we excluded this size distribution from further analysis as it could not be corrected.

\section{Results and discussion}

\subsection{The effect of the Mie correction to the channel widths of the FM-100}

It is remarkable that the Mie channels were rather wide and overlapped especially in the range where we expect most of the droplets ( 3 to $20 \mu \mathrm{m}$; see Bruijnzeel et al., 2005). But, the default procedure of deducing the channel thresholds (as it is done by the manufacturer) did not result in substantially different mean points, indicating that the $\mathrm{LWC}_{\text {geo }}$ would not differ a lot from $\mathrm{LWC}_{\mathrm{dft}}$. However, a proper error estimation of the $\mathrm{LWC}_{\mathrm{FM}}$ for the sizing uncertainty arising due to the non-monotonic Mie scattering curve can be deduced from the Mie channels. Consequently, our suggestion is to use the Mie channel approach if one is interested in the LWC including maximal error assumptions and not only in the $N$.

The effect of the Mie channel configuration on two typical droplet size distributions for maritime and continental low stratus clouds described by a log normal distribution $\left(n_{\log }\right)$ is shown in Fig. 6a and c. We used

$n_{\log }(D)=\frac{N_{\mathrm{t}, \log }}{\sqrt{2 \pi} \sigma_{\log } D} \exp \left\{\frac{-\left[\ln \left(D / D_{\mathrm{n}, \log }\right)\right]^{2}}{2 \sigma_{\log }^{2}}\right\}$,

with $\quad N_{\mathrm{t}, \log }=288 \mathrm{~cm}^{-3}, \quad \sigma_{\log }=0.38$ and $D_{\mathrm{n}, \log }=7.7 \mu \mathrm{m}$ for continental and $N_{\mathrm{t}, \log }=74 \mathrm{~cm}^{-3}, \quad \sigma_{\log }=0.38$ and $D_{\mathrm{n}, \log }=13.1 \mu \mathrm{m}$ for maritime droplet size distributions (according to Miles et al., 2000).

For this purpose we modeled the sampling behavior of the FM-100 by first translating the droplet size $(D)$ into a scattering signal using the Mie band. If the Mie band of $(D)$ fell into more than one channel, $n_{\log }(D)$ was distributed proportional to the coverage of the Mie band in comparison to the channel height over the involved channels. The received distribution was what the FM-100 would measure and was then translated into a droplet size distribution by attributing the default diameter $\left(D_{\mathrm{dft}}\right)$ or the Mie diameter $\left(D_{\mathrm{geo}}\right)$ to the channel. The droplet size distribution for the default channels $\left(n_{\mathrm{dft}}\right)$ was shifted towards larger droplets for the continental size distribution (Fig. 6a) while for the maritime distribution the shape was in rather good agreement except for some spikes between 10 and $15 \mu \mathrm{m}$ which are similar to those that have been recently discussed as an artifact from Mie scattering (Baumgardner et al., 2010). This simulation supports the assumption that spikes like these are indeed an artifact resulting from Mie scattering. The distribution based on the Mie channels $\left(n_{\text {geo }}\right)$ is plotted with horizontal error bars indicating the width of the new channels (Fig. 6a and c). As these channels were wider than the default ones, the droplet size distribution was flatter. However, it is obvious that this is not an appropriate approach if one is interested in droplet size distributions as the Mie channels overlap. For this aim it is more useful to use the method presented in Sect. 3.1.2, which is shown in Fig. $6 \mathrm{~b}$ and d. The Mie oscillations were still obvious in 

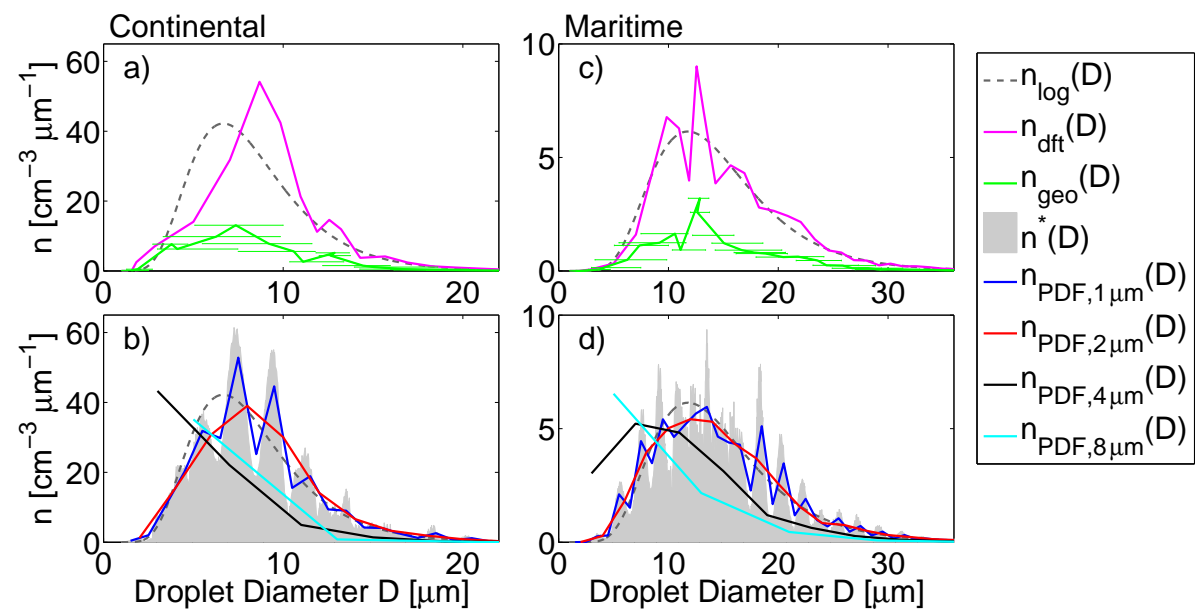

Fig. 6. Modeled sampling behavior of the FM-100 as described in Sect. 4.3.1 for an assumed typical continental (left panels) and maritime (right panels) cloud droplet size distribution $n_{\log }(D)$ (gray dashed lines). (a) and (c) Size distribution measured with default channels $\left(n_{\mathrm{dft}}(D)\right.$, magenta line) and the Mie channels $\left(n_{\text {geo }}(D)\right.$, green line) including maximal and minimal errors for each channel (see Sect. 3.1.1). (b) and (d) Effect of the re-sizing on the apparent size distribution: the discrete droplet number distribution $n^{*}(D)$ with a resolution of $0.02 \mu \mathrm{m}$ (gray area) and four different re-binned size distributions $n_{\mathrm{PDF}, a \mu \mathrm{m}}$ with bin size $\Delta D=a \mu \mathrm{m}(a=1,2,4$ and 8 , see Sect. 3.1.2 for details).

$n^{*}(D)$ (droplet number concentration with a resolution of $0.02 \mu \mathrm{m}$, Eq. 6) and $n_{\mathrm{PDF}, 1 \mu \mathrm{m}}\left(n_{\mathrm{PDF}, a \mu \mathrm{m}}\right.$ refers to channels with bin size $\Delta D=a \mu \mathrm{m})$. However, the original curve $n_{\log }$ was adequately represented, if a bin size of $2 \mu \mathrm{m}\left(n_{\mathrm{PDF}, 2 \mu \mathrm{m}}\right)$ was used for the re-binning. For larger bin sizes used for the re-binning $-4 \mu \mathrm{m}\left(n_{\mathrm{PDF}, 4 \mu \mathrm{m}}\right)$ and $8 \mu \mathrm{m}\left(n_{\mathrm{PDF}, 8 \mu \mathrm{m}}\right)-$ the shape of $n_{\log }$ could no longer be adequately represented.

Based on this theoretical exercise, we conclude that using the probability density function method with a bin size of $2 \mu \mathrm{m}$ is the best compromise if one is interested in droplet size distributions. The effect of this new approach on the measured $\mathrm{LWC}_{\mathrm{FM}}$ will be presented and discussed in Sect. 4.3.

\subsection{Particle loss mechanisms in the FM-100}

Figure 7 shows the efficiencies for the different particle loss mechanisms calculated for the FM-100 under standard atmospheric conditions $\left(T=0^{\circ} \mathrm{C}, P=1013 \mathrm{hPa}\right)$ for horizontal sampling using the formulas introduced in Appendix A. The $\eta_{\text {asp }}$ and $\eta_{\text {trm }}$ were close to one for droplets smaller than $\approx 20 \mu \mathrm{m}$ independent of the wind speed regime. In the calm air regime (Fig. $7 \mathrm{c} ; U_{0}<0.5 \mathrm{~m} \mathrm{~s}^{-1}$ ), $\eta_{\text {asp }}$ was independent of wind speed $\left(U_{0}\right)$ and sampling angle $\theta_{\mathrm{s}}$. However, $\eta_{\text {asp,calm }}$ decreased below 0.5 for droplets larger than $38 \mu \mathrm{m}$. In both, the moving air regime (Fig. 7a) and the slow moving air regime (Fig. 7b) $\eta_{\text {asp }}$ decreased with increasing $\theta_{\mathrm{s}}$ and increasing droplet diameter. Additionally, the transition from Eqs. (A1) to (A3) was obvious at $60^{\circ}$ sampling angle. This step showed a rather unphysical behavior from $R_{\mathrm{V}}=0.11$ to 0.8 as particles of the same size with sampling angles larger than $60^{\circ}$ would reach the inlet with a higher probability than those with angles below $60^{\circ}$. Both equations were deduced from experiments at discrete sampling angles $\left(\theta_{\mathrm{s}}=0^{\circ}, 30^{\circ}, 45^{\circ}, 60^{\circ}\right.$ and $\left.90^{\circ}\right)$. Additionally, Eq. (A3) was originally only suggested for sub-kinetical sampling $\left(1.25 \leq R_{\mathrm{v}} \leq 6.25 ; 0.003 \leq S t k \leq 0.2\right.$, Hangal and Willeke, 1990a) while Eq. (A1) fitted the measured data with $0.25 \leq R_{\mathrm{v}} \leq 2 ; 0.01 \leq S t k \leq 6$ (Durham and Lundgren, 1980; Hangal and Willeke, 1990a) except for $\theta_{\mathrm{s}}=90^{\circ}$. However, Eq. (A3) has been used recently for a much wider $R_{\mathrm{v}}$ range (von der Weiden et al., 2009; Brockmann, 2011). Nevertheless, we are interested in a reasonable physical description for the loss corrections for the FM-100 and we therefore decided to use Eq. (A1) for $0 \leq \theta_{\mathrm{S}}<90^{\circ}$ as an additional option for particle loss corrections as this could also be deduced as the valid range based on the comparison to measurements (Durham and Lundgren, 1980; Hangal and Willeke, 1990a). By doing so, we also avoid that $\eta_{\text {asp }}$ could not be calculated due to Stokes limitations as Eq. (A1) has a broader validity range than Eq. (A3).

For the $\eta_{\text {trm }}$ one panel for super-kinetical sampling (Fig. 7d) and one for sub-kinetical sampling (Fig. 7e) is shown as those two regimes differ in terms of loss mechanisms due to the formation of the vena contracta in the super-kinetical regime. In the sub-kinetical regime, $\eta_{\text {trm }}$ decreased quickly for droplets larger than around $10 \mu \mathrm{m}$ and angles larger than $30^{\circ}$. For larger $R_{\mathrm{V}}$ this transition decreased to smaller sampling angles and smaller droplet diameters. In the super-kinetical regime $\left(R_{\mathrm{V}}<1\right)$, the formation of the vena contracta decreased $\eta_{\text {trm }}$ for smaller angles in a way that $\eta_{\text {trm }}$ was nearly independent of the sampling angle. In recent publications (von der Weiden et al., 2009; Brockmann, 2011), Eq. (A9) was stated to only be 

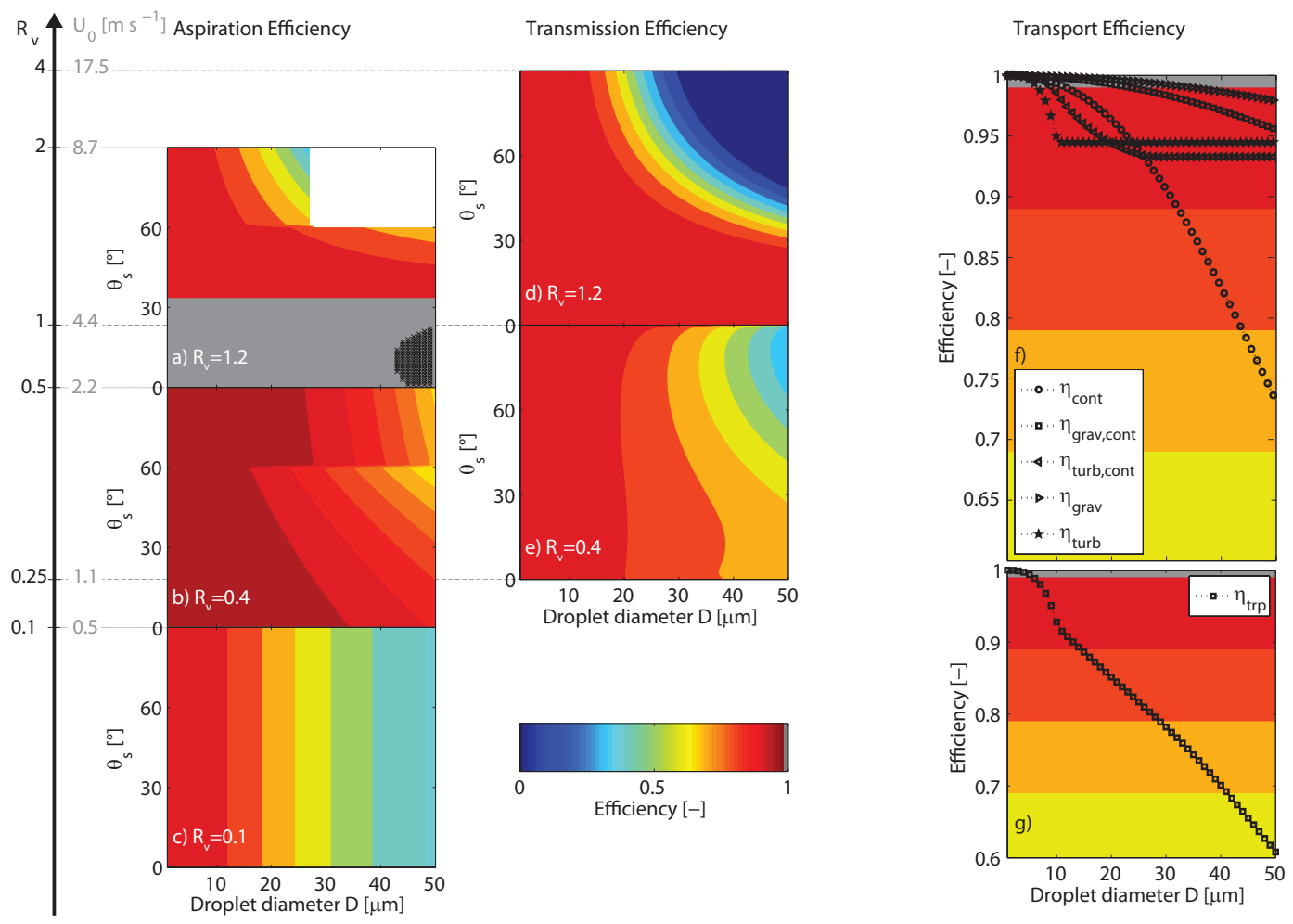

Fig. 7. Efficiencies for the different particle loss mechanisms for the FM-100 calculated under standard atmospheric conditions ( $p=1013 \mathrm{mbar}, T=0^{\circ} \mathrm{C}$ ) using the equations presented in Appendix A for sampling angles $\theta_{\mathrm{S}} \in\left[0^{\circ}, 90^{\circ}\right]$. For gray colors the efficiency is 1 , decreasing from 0.99 (red) to 0 (blue), shaded area indicates efficiency $>1.05$. White indicates that the efficiencies could not be calculated, as the input variables were not inside the range of validity. For each velocity range of $\eta_{\text {asp }}$, one representative panel (values in brackets) is shown: (a) moving air $\left(U_{0}=5.24 \mathrm{~m} \mathrm{~s}^{-1}\right.$ which corresponds to a velocity ratio $\left.R_{\mathrm{V}}=U_{0} / U=1.2\right)$, (b) slow moving air $\left(U_{0}=1.7 \mathrm{~m} \mathrm{~s}{ }^{-1}\right.$ which is equal to $\left.R_{\mathrm{V}}=0.4\right)$ and (c) calm air $\left(U_{0}=0.43 \mathrm{~m} \mathrm{~s}^{-1}\right.$ which corresponds to a velocity ratio $R_{\mathrm{V}}$ of 0.1$)$. For $\eta_{\text {trm }}$ one panel for sub-kinetical sampling (d) and one for super-kinetical sampling (e) is shown. The positioning of the panels (a) to (e) versus the $R_{\mathrm{V}}$-axis on the left represents the range of the different velocity ranges for $\eta_{\text {asp }}$ and $\eta_{\text {trm }}$. The different mechanisms contributing $\left(\eta_{\text {cont }}, \eta_{\text {grav,cont }}, \eta_{\text {turb,cont }}, \eta_{\text {grav }}\right.$ and $\eta_{\text {turb }}$ ) to transport efficiency $\eta_{\text {tsp }}$ are shown individually in (f) and cumulative in (g).

valid for $R_{\mathrm{v}}>0.25$ (corresponding to $U_{0}=1.1 \mathrm{~m} \mathrm{~s}^{-1}$ ), although there were no such limitations in the original publication (Hangal and Willeke, 1990b). As wind speeds are often very low in fogs (especially in radiation fogs; Fuzzi et al., 1985) this would mean that particle losses could not be calculated for this range and could not be used for further analysis. There are, however, two options available as an approximation to solve this issue: (1) we set $\eta_{\text {trm }}=1$ for $R_{\mathrm{V}}<0.25$ and consider the calculated $\eta_{\mathrm{tot}}$ as an upper limit, or (2) we use Eq. (A9) also for $R_{\mathrm{V}}<0.25$. A careful analysis of Eq. (A9) for $R_{\mathrm{v}}<0.25$ for the FM-100 revealed that $\eta_{\text {trm }}$ got closer to one for decreasing $R_{\mathrm{v}}$ and that therefore possibility (2) should be considered the more appropriate one. Nevertheless, we included both versions of $\eta_{\text {trm }}$ for our analysis of the CLACE 2010 data and will refer to the two options with TR1 to case (1) and TR to case (2).

The dominating contribution to the $\eta_{\text {tsp }}$ was $\eta_{\text {cont }}$, while $\eta_{\text {grav }}$ and $\eta_{\text {turb }}$ for the contraction part as well as for the wind tunnel did not decrease below 0.95 (Fig. 7f). However, the product of all five loss mechanisms $\eta_{\text {tsp }}$, already decreased below 0.9 for droplets around $14 \mu \mathrm{m}$, emphasizing that particle losses within the FM-100 should not be neglected even if the FM-100 is placed on a turning table.

The resulting $\eta_{\text {tot }}$ with the implementation of $\eta_{\text {trm }}$ for the whole super-kinetical regime and $\eta_{\text {asp }}\left(0-90^{\circ}\right)=\eta_{\text {asp }}\left(0-60^{\circ}\right)$ (later on referred to as ASP09TR) for the three different $R_{\mathrm{V}}$ regimes treated above are shown in Fig. 8a to c. Independent of the wind regime, $\eta_{\text {tot }}>0.9$ for droplets smaller than $10 \mu \mathrm{m}$. Interestingly, for droplets larger than $10 \mu \mathrm{m} \eta_{\text {tot }}$ decreased fastest with droplet size for the slow moving regime. So the common idea that sampling in calm air does not need any corrections for particle losses might be correct for aerosols, but for droplets, corrections appear to be essential. In the moving air regime $\eta_{\text {tot }}$ decreased with sampling angle. While for the slow motion regime the sampling angle played a minor role in comparison to the droplet size, in the moving regime, $\eta_{\text {tot }}$ rapidly decreased with increasing sampling angle. The counter-intuitive fact, that $\eta_{\text {tot }}$ for $R_{\mathrm{v}}>1$ was higher 


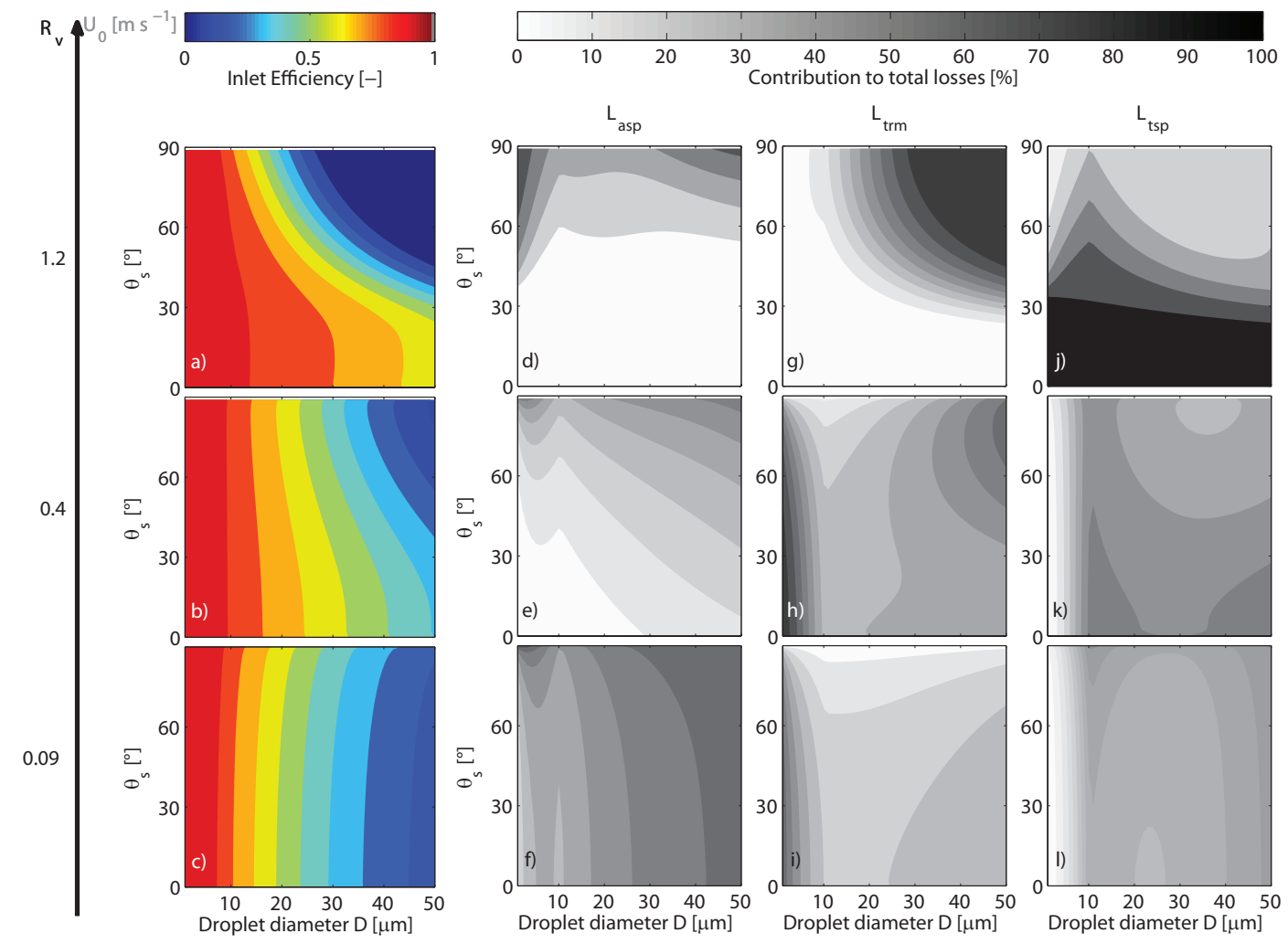

Fig. 8. (a) to (c) Total inlet efficiencies as a function of sampling angle $\theta_{\mathrm{S}}$ versus droplet diameter $D$ for three different representative velocities $\left(R_{\mathrm{V}}=1.2,0.4\right.$ and 0.09$)$ of each velocity range. The individual percentaged contributions of aspiration losses (d) to (f), transmission losses (g) to (i) and transport losses (j) to (l) are shown as percentaged values (see black and white color bar).

for larger droplets for sampling angles below $\approx 30^{\circ}$ than for $R_{\mathrm{V}}<1$, could be explained in the way that $\eta_{\text {asp }}$ increases above 1 in the sub-kinetical regime, which increased $\eta_{\text {tot }}$. Nevertheless, $\eta_{\text {tot }}$ was never above one for the regime we correct.

The contributions of the different loss mechanisms to the overall losses $\left(L_{\text {asp }}=\frac{1-\eta_{\text {asp }}}{1-\eta_{\text {tot }}}, L_{\text {trm }}=\frac{1-\eta_{\text {trm }}}{1-\eta_{\text {tot }}}\right.$, and $L_{\text {tsp }}=\frac{1-\eta_{\text {tsp }}}{1-\eta_{\text {tot }}}$; Fig. 8d to l) depend on $R_{\mathrm{V}}$, sampling angle and droplet diameter. For $R_{\mathrm{v}}>1$ and sampling angles below $\approx 30^{\circ}$, the losses were dominated by particle losses within the FM-100 as $L_{\text {trp }}$ was 1 (Fig. $8 \mathrm{j}$ to 1 ). For $R_{\mathrm{v}}>1$ and sampling angles above $30^{\circ}$ and droplet diameters $>20 \mu \mathrm{m}$ losses were dominated by transmission losses $L_{\text {trm }}$, with a small contribution of aspiration losses $L_{\text {asp. }}$. In the slow moving regime, the contributions of the different mechanisms were comparable. However, in the calm regime for droplets $\gtrsim 15 \mu \mathrm{m}$, most losses happen due to aspiration.

To summarize, based on the theoretical framework of the description of particle loss mechanisms, it is important to consider particle losses when it comes to droplet size measurements with the FM-100. Losses of $40 \%$ for droplets $\approx 20 \mu \mathrm{m}$ should be expected for calm air $\left(U_{0}<0.5 \mathrm{~m} \mathrm{~s}^{-1}\right)$. The losses decrease with increasing wind speeds for sampling angles $\lesssim 30^{\circ}$ and increase for sampling angles $\gtrsim 30^{\circ}$.
In the sub-kinetical regime, the sampling angle is the critical parameter when it comes to particle losses. We therefore assume that it is more appropriate to evaluate the quality of the collected data with the presented approach, then to directly exclude data collected under larger sampling angles as we could show that even droplets collected at small sampling angles can be subject to major particle losses due to losses in the FM-100 as well as due to non-isokinetical sampling.

In the next section these loss calculations will be used to correct measured data from the CLACE 2010 campaign. We evaluated the particle losses for the four different categories summarized in Table 3.

\subsection{Implementation of the Mie corrections and the particle losses for the CLACE 2010 campaign}

The effect of the different corrections for particle losses and re-sizing as discussed in the previous sections on the CLACE 2010 data will be described in this section.

In order to evaluate our procedure of error attribution due to Mie scattering as well as due to particle losses, we apply our corrections to measured cloud droplet spectra from CLACE 2010. In contrast to Lance et al. (2010, who only used data with $\mathrm{LWC}>100 \mathrm{mg} \mathrm{m}^{-3}$ ), we decided to choose a rather weak cloud criterion. The presence of a cloud was 
Table 3. Description of the different particle loss categories applied to the CLACE 2010 data.

\begin{tabular}{ll}
\hline Abbreviation & Description \\
\hline STANDARD & $\eta_{\text {tot }}$ based on the equations from Appendix A \\
TR1 & similar as STANDARD except $\left(R_{\mathrm{V}}<0.25\right)=1$ \\
TR & similar as STANDARD except $\left(R_{\mathrm{V}}<0.25\right)$ continued \\
ASP09TR & similar as STANDARD except $\left(R_{\mathrm{V}}<0.25\right)$ continued and $\eta_{\text {asp }}\left(0-90^{\circ}\right)=\eta_{\text {asp }}\left(0-60^{\circ}\right)$ \\
\hline
\end{tabular}
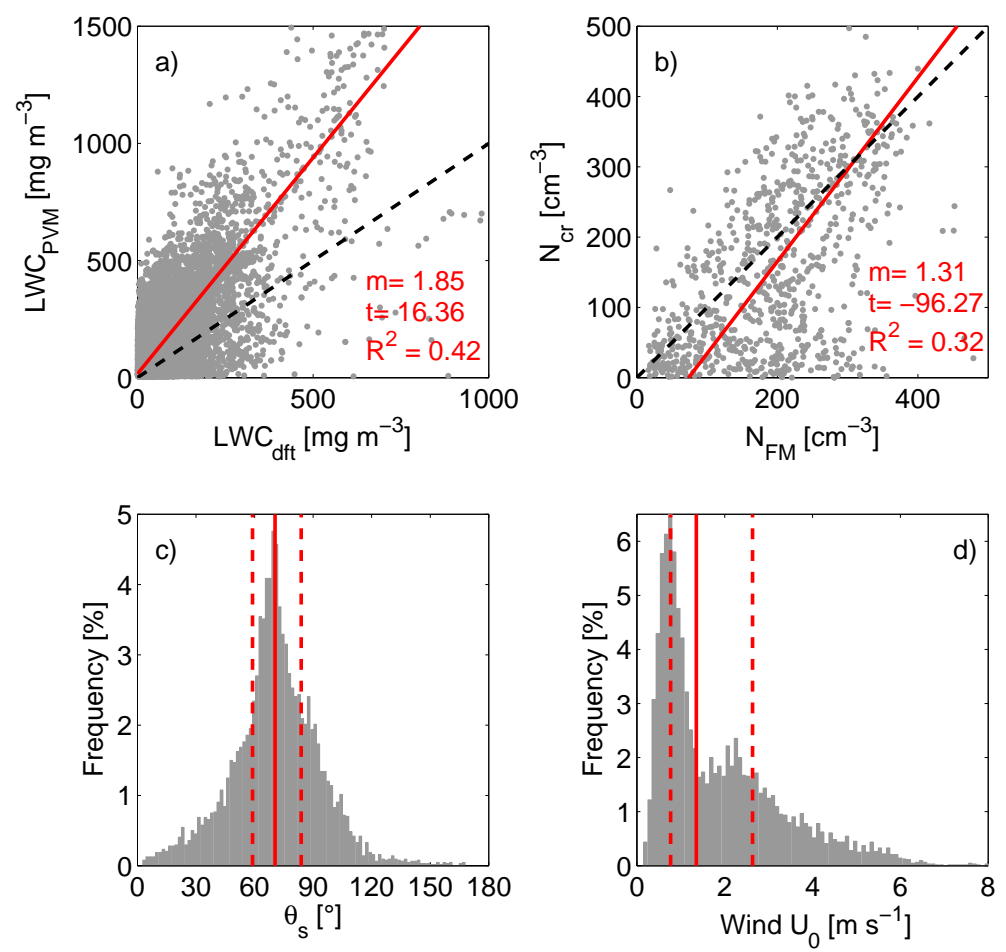

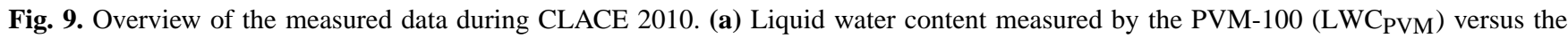
FM-100 measurements using the default channel configuration $\left(\mathrm{LWC}_{\mathrm{dft}}\right)$; (b) number concentrations of cloud residuals $\left(N_{\mathrm{cr}}\right)$ versus cloud droplet number concentration measured by the FM-100 $\left(N_{\mathrm{FM}}\right)$. The solid red line in (a) and (b) represents a geometric mean regression with $m$ : slope, $t$ : intercept and $R^{2}$ : squared correlation coefficient. (c) Frequency of observed sampling angle $\theta_{\mathrm{S}}$; (d) frequency of observed horizontal wind speed $U_{0}$. Both parameters were determined by ultrasonic measurements. The solid red line represents the median, while the dashed lines show the 25 th and 75 th percentile, respectively.

defined if the one minute mean values fulfilled the following criterion: $\mathrm{LWC}_{\mathrm{PVM}}>5 \mathrm{mg} \mathrm{m}^{-3}$ and $N_{\mathrm{FM}}>10 \mathrm{~cm}^{-3}$. We are aware of the risk of including very thin and hence inhomogeneous clouds by using this criterion, which might cause problems for comparing the LWC results especially at low values. We also tried to use a stricter cloud criterion in terms of higher thresholds, but found a strong selection bias in such comparisons and hence decided to keep the threshold as low as possible. Due to the mounting position of the FM-100, the inlet often was completely closed by frozen cloud droplets as the cold and humid updraft blew into the inlet of the FM-100. We therefore excluded periods with temperatures below $0{ }^{\circ} \mathrm{C}$ from data evaluation in order to exclude potential measurement artifacts that might arise due to freezing.
The cloud criterion was fulfilled for $106 \mathrm{~h}$ of the CLACE 2010 campaign (data collection period 56 days). During $71 \mathrm{~h}$ of the cloudy period (which was $66 \%$ of the cloud time), the FM-100 was positioned horizontally. An overview of the LWC and the $N$ during cloud sampling as well as the wind conditions around the FM-100 inlet are shown in Fig. 9. We chose geometric mean regressions as a tool to compare the LWC and $N$ as we assume that all methods used to deduce LWC and $N$ were error-prone. Based on the geometric mean regression, the FM-100 measured a smaller LWC than the PVM-100 (Fig. 9a). A comparison of the LWC $\mathrm{PVM}_{\mathrm{P}}$ with the CWC $\left(R^{2}=0.59\right.$, with slope $m=0.93$ and intercept $t=0$ not shown) revealed a good agreement between the two alternative approaches to measure the LWC. Hence, the PVM-100 can be considered an 

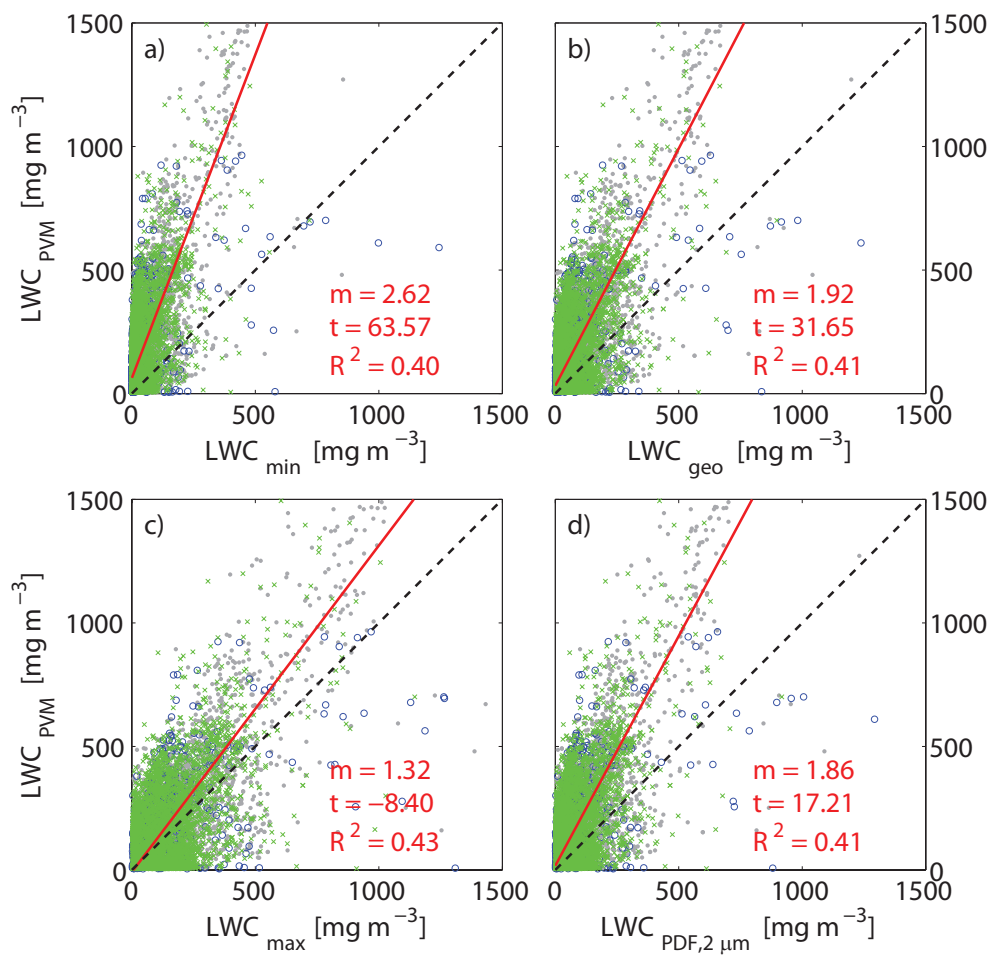

- calm regime $\times$ slow motion regime $\left(\theta_{s}>60^{\circ}\right) \quad \cdot$ other data

Fig. 10. Effect of the Mie corrections on the LWC during CLACE 2010 (blue circle: $U_{0}<0.5 \mathrm{~m} \mathrm{~s}^{-1}$; green crosses: $0.5<R_{\mathrm{V}}<0.8$ and $\theta_{\mathrm{S}}>60^{\circ}$; gray dots: rest of the data fulfilling the cloud criterion). (a) to (c) LWC measured by the PVM-100 (LWC

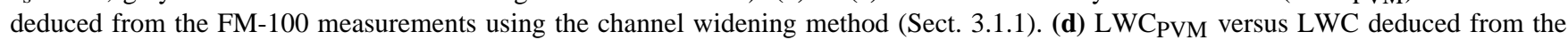
FM-100 measurements using the stochastic approach (Sect. 3.1.2). The solid red line represents a geometric mean regression to the entire data with $m$ : slope, $t$ : intercept and $R^{2}$ : squared correlation coefficient.

appropriate reference to validate our corrections for the FM100 measurements. The sampling angle of the FM- 100 was large during most of the time, such that only $4 \%$ of the cloudy data were within the sampling angle criteria (below $30^{\circ}$ ) used by Westbeld et al. (2009). This is remarkable, as the inlet faced the expected mean wind direction during the first part of the campaign. Nevertheless, the median horizontal sampling angle during the first part was $38^{\circ}$, indicating that the mean wind direction as measured by MeteoSwiss was not representative for the wind field at the FM-100 mounting position. The high vertical sampling angle (median $42^{\circ}$ relative to the FM-100), which resulted from strong updrafts, contributed additionally leading to the high sampling angles (Fig. 9d). Based on the sampling angles and the analysis presented in Sect. 4.2, we expect that significant particle losses during sampling could explain the difference between $\mathrm{LWC}_{\mathrm{FM}}$ and $\mathrm{LWC} \mathrm{CVM}_{\mathrm{P}}$, although the wind speed was not too high (Fig. 9d). However, from the comparison of $N_{\mathrm{cr}}$ to $N_{\mathrm{FM}}$, we would not necessarily expect large particle losses (see Fig. 9b). Therefore, we will first present the effect of resizing in order to investigate whether improper sizing could explain the lower $\mathrm{LWC}_{\mathrm{FM}}$ before continuing with the effect of particle losses.

\subsubsection{Corrections for droplet sizing and its effect on $\mathbf{L W C}_{\mathbf{F M}}$}

The difference between $D_{\text {geo }}$ and $D_{\mathrm{dft}}$ was minor (Sect. 4.1), so the regression lines for $\mathrm{LWC}_{\mathrm{geo}}$ and $\mathrm{LWC}_{\mathrm{dft}}$ were similar (Figs. 9a and 10b). However, the spread of the $\mathrm{LWC}_{\mathrm{FM}}$ based on $D_{\text {geo }}$ was large if we consider $\mathrm{LWC}_{\min }$ (Fig. 10a) as a minimal estimate and $\mathrm{LWC}_{\max }$ as an upper estimate (Fig. 10c) of the $\mathrm{LWC}_{\mathrm{FM}}$. Nevertheless, the linear regression line of $\mathrm{LWC}_{\mathrm{PVM}}$ versus $\mathrm{LWC}_{\max }$ was still clearly different from unity, meaning that even within the range of maximal error assumption $\left(\mathrm{LWC}_{\mathrm{FM}} \in\left[\mathrm{LWC}_{\min }, \mathrm{LWC}_{\mathrm{max}}\right]\right.$ ), the difference between $\mathrm{LWC}_{\mathrm{PVM}}$ and $\mathrm{LWC}_{\mathrm{FM}}$ could not be explained by incorrect sizing.

A similar conclusion can be drawn from the comparison of the LWC based on probability density functions with different bin sizes for re-binning: the slope and intercept were in the same range as for $\mathrm{LWC}_{\mathrm{dft}}$ and $\mathrm{LWC}_{\mathrm{geo}}$; the same was true for the squared Pearson correlation coefficient $R^{2}$ (see Table 4). The $\mathrm{LWC}_{\mathrm{FM}}$ was still in the appropriate range, if 
Table 4. Slope, intercept and $R^{2}$ for geometric mean regressions between $L W C_{P V M}$ and $L_{W} C_{\text {geo }}$ as well as $L W C_{P D F}, a \mu m$ for non-corrected data as well as for the different correction categories presented in Table 3. Brackets indicate whether all cloud data from CLACE 2010 (all) or only data during horizontal sampling (hori) or downward sampling (down) were used.

\begin{tabular}{|c|c|c|c|c|c|c|c|c|c|c|}
\hline & \multicolumn{2}{|c|}{$\mathrm{LWC}_{\text {geo }}$} & \multicolumn{2}{|c|}{$\mathrm{LWC}_{\mathrm{PDF}, 1 \mu \mathrm{m}}$} & \multicolumn{2}{|c|}{$\mathrm{LWC}_{\mathrm{PDF}, 2 \mu \mathrm{m}}$} & \multicolumn{2}{|c|}{$\mathrm{LWC}_{\mathrm{PDF}, 4 \mu \mathrm{m}}$} & \multicolumn{2}{|c|}{$\mathrm{LWC}_{\mathrm{PDF}, 8 \mu \mathrm{m}}$} \\
\hline & slope & intercept & slope & intercept & slope & intercept & slope & intercept & slope & intercept \\
\hline \multirow[t]{2}{*}{ non-corrected (all) } & 92 & 31. & 84 & 21 & 86 & & 1.86 & 18 & 1.95 & 24.81 \\
\hline & \multicolumn{2}{|c|}{$R^{2}=0.41$} & \multicolumn{2}{|c|}{$R^{2}=0.42$} & \multicolumn{2}{|c|}{$R^{2}=0.41$} & \multicolumn{2}{|c|}{$R^{2}=0.41$} & \multicolumn{2}{|c|}{$R^{2}=0.40$} \\
\hline \multirow[t]{2}{*}{ non-corrected (hori) } & 1.99 & 5.7 & 1.91 & -4.89 & 1.93 & -9.99 & 1.94 & -8.45 & 2.06 & -4.72 \\
\hline & \multicolumn{2}{|c|}{$R^{2}=0.47$} & \multicolumn{2}{|c|}{$R^{2}=0.47$} & \multicolumn{2}{|c|}{$R^{2}=0.46$} & \multicolumn{2}{|c|}{$R^{2}=0.46$} & \multicolumn{2}{|c|}{$R^{2}=0.45$} \\
\hline non-corrected (down) & 1.76 & 84.81 & 1.69 & 74.61 & 1.69 & 72.74 & 1.70 & 74.43 & 1.73 & 83.35 \\
\hline \multirow[t]{2}{*}{ STANDARD (all) } & 29 & -19.23 & 1.2 & -21.86 & 1.24 & -30.09 & 1.24 & -32.56 & 1.25 & -29.24 \\
\hline & \multicolumn{2}{|c|}{$R^{2}=0.49$} & \multicolumn{2}{|c|}{$R^{2}=0.42$} & \multicolumn{2}{|c|}{$R^{2}=0.45$} & \multicolumn{2}{|c|}{$R^{2}=0.62$} & \multicolumn{2}{|c|}{$R^{2}=0.59$} \\
\hline \multirow[t]{2}{*}{ STANDARD (hori) } & 1.37 & -35.12 & 1.28 & -38.76 & 1.32 & -48 & 1.28 & -45.6 & 1.3 & -42.99 \\
\hline & \multicolumn{2}{|c|}{$R^{2}=0.56$} & \multicolumn{2}{|c|}{$R^{2}=0.48$} & \multicolumn{2}{|c|}{$R^{2}=0.51$} & \multicolumn{2}{|c|}{$R^{2}=0.67$} & \multicolumn{2}{|c|}{$R^{2}=0.65$} \\
\hline \multirow[t]{2}{*}{ STANDARD (down) } & 0.91 & 56.99 & 0.89 & 51.28 & 0.89 & 50.46 & 0.89 & 49.8 & 0.88 & 54.09 \\
\hline & \multicolumn{2}{|c|}{$R^{2}=0.23$} & \multicolumn{2}{|c|}{$R^{2}=0.24$} & & $=0.24$ & & $=0.25$ & & $=0.22$ \\
\hline TR1 (all) & 1.32 & 50.97 & 1.27 & 43.27 & 1.28 & 39.07 & 1.22 & 41.47 & 1.24 & 46.37 \\
\hline & & $=0.30$ & & $=0.26$ & & $=0.28$ & & $=0.42$ & & $=0.39$ \\
\hline TR (all) & 1.29 & 50.75 & 1.24 & 43.35 & 1.25 & 38.91 & 1.21 & 40.11 & 1.22 & 44.93 \\
\hline & & $=0.29$ & & $=0.25$ & & $=0.27$ & & $=0.42$ & & $=0.39$ \\
\hline ASP09TR (all) & 1.18 & 54.94 & 1.14 & 45.33 & 1.15 & 41.90 & 1.14 & 44.53 & 1.12 & 52.23 \\
\hline & & $=0.39$ & & $=0.39$ & & $=0.39$ & & $=0.39$ & & $=0.36$ \\
\hline ASP09TR (hori) & 1.17 & 31.63 & 1.13 & 22.18 & 1.15 & 17.95 & 1.13 & 21.14 & 1.10 & 29.30 \\
\hline & & $=0.49$ & & 0.49 & & $=0.48$ & & $=0.49$ & & $=0.46$ \\
\hline ASP09TR (down) & 1.17 & 107.27 & 1.14 & 97.62 & 1.13 & 96.13 & 1.13 & 97.24 & 1.14 & 103.34 \\
\hline & & 0.21 & & 0.23 & & $=0.23$ & & $=0.23$ & & $=0.21$ \\
\hline
\end{tabular}

the bin width $>2 \mu \mathrm{m}$ was used, although the size distribution was no longer appropriately represented (Sect. 4.1). So, independent of how we derived the droplet size distributions from our measured signal, the $\mathrm{LWC}_{\mathrm{FM}}$ did not rise to a level suggested by $\mathrm{LWC}_{\mathrm{PVM}}$.

Interestingly, the correlation between $\mathrm{LWC}_{\mathrm{FM}}$ and $\mathrm{LWC}_{\mathrm{PVM}}$ is higher for horizontal sampling in comparison to the downward sampling period (see Table 4). As the sampled cloud time for horizontal sampling was nearly twice as long as for downward sampling, we do not consider this as an error that can be related to counting statistics. We rather take this as an additional indicator of particle losses for downward sampling conditions as the gravitational losses are supposed to be higher. After particle loss corrections this difference should vanish. Consequently, for the CLACE 2010 data, particle losses during sampling could be considered as the main reason for the under-sampling of the FM-100, although this was not expected based on droplet number concentrations.

As a general conclusion, the influence of the presented sizing correction methods is negligible, if the LWC is the only quantity of interest. However, if an error estimation of $\mathrm{LWC}_{\mathrm{FM}}$ is an object of the study, then $\mathrm{LWC}_{\text {geo }}$ with the maximal error assumption by $\mathrm{LWC}_{\mathrm{FM}} \in\left[\mathrm{LWC}_{\min }, \mathrm{LWC}_{\max }\right]$ should be used; if one is interested in size distributions, LWC $C_{\text {PDF }, 2 \mu \mathrm{m}}$ should be used.

\subsubsection{Changes of $\mathrm{LWC}_{\mathrm{FM}}$ due to particle loss corrections}

Table 4 summarizes the results of the different particle loss corrections. For the STANDARD correction the correlation slightly increased as a result of the decreasing fraction of cloud data that could be corrected (around $42 \%$ of cloud data). Reasons why the correction could not be applied were either that the sampling angle $>90^{\circ}$ ( $11 \%$ of the cloud data), $R_{\mathrm{V}}$ was smaller than 0.25 (42\% of cloud data) or droplets with Stokes numbers larger than the Stokes limitations were abundant ( $5 \%$ of the cloud data). For horizontal sampling the numbers were similar, while for downward sampling only around $20 \%$ of the cloud data could be corrected as most of the data fell into the $R_{\mathrm{V}}<0.25$ regime. However, the corrections for the remaining downward sampling data were such that $\mathrm{LWC}_{\text {geo }}$ as well as $\mathrm{LWC}_{\mathrm{PDF}, a \mu \mathrm{m}}$ were similar to $\mathrm{LWC}_{\mathrm{PVM}}$. Although this is a promising result, it needs to be treated with care, as first, the correlation was small $\left(R^{2} \approx 0.2\right.$ ), second, the LWC was always below $700 \mathrm{mg} \mathrm{m}^{-3}$ and third, the counting statistics was small. Besides the fact that we could only correct around $40 \%$ of the CLACE 2010 data with this correction, the agreement between $\mathrm{LWC}_{\text {geo }}$ and $\mathrm{LWC}_{\mathrm{PVM}}$ as well as between $\mathrm{LWC}_{\mathrm{PDF}, a \mu \mathrm{m}}$ and $\mathrm{LWC}_{\mathrm{PVM}}$ improved, but still differed from one. 

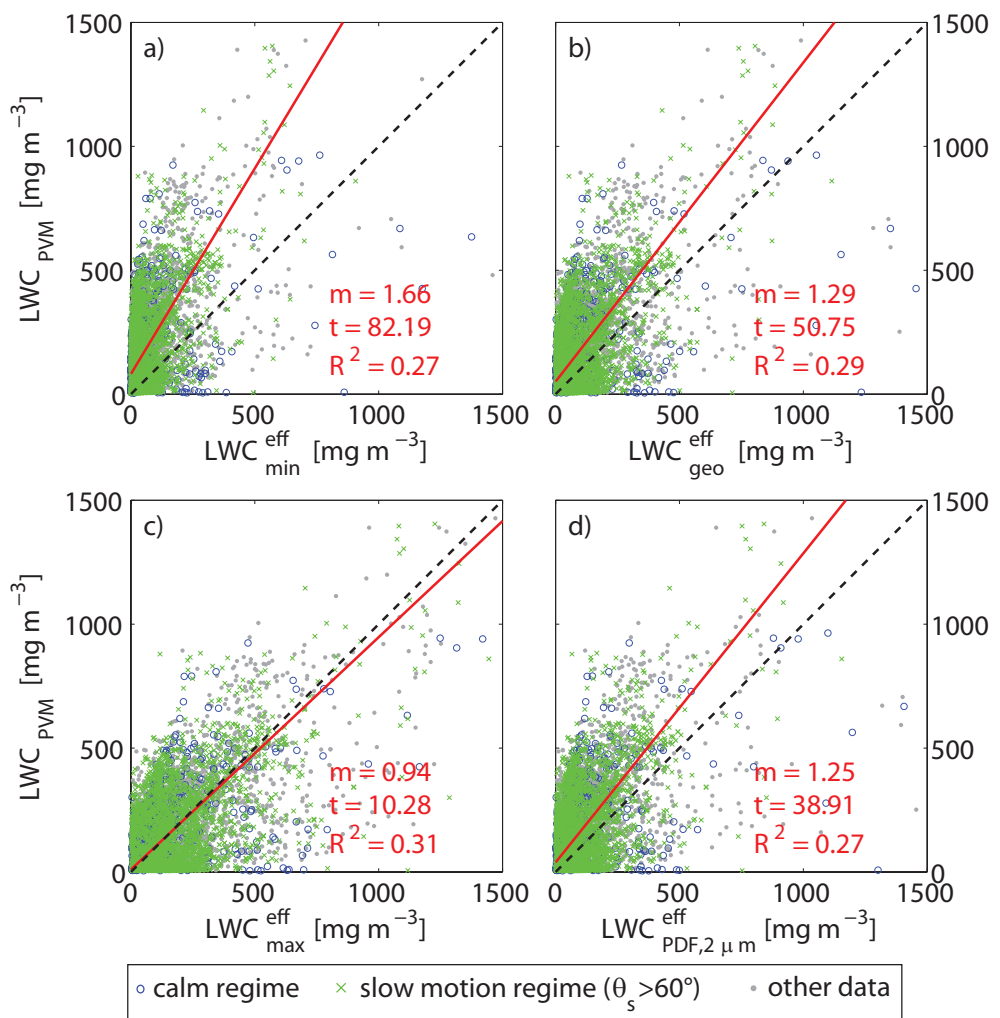

Fig. 11. Effect of particle losses (using TR corrections - see Table 3 - for all data) on the $\mathrm{LWC}$ for $\mathrm{LWC}_{\min }, \mathrm{LWC}_{\mathrm{geo}}, \mathrm{LWC}_{\mathrm{max}}$ and ${ }_{\text {LWC }}$ PDF $2 \mu \mathrm{m}$ for CLACE 2010 (blue circle: $U_{0}<0.5 \mathrm{~m} \mathrm{~s}^{-1}$; green crosses: $0.5<R_{\mathrm{V}}<0.8$ and $\theta_{\mathrm{S}}>60^{\circ}$; gray dots: rest of the data fulfilling the cloud criterion). The solid red line represents a geometric mean regression with $m$ : slope, $t$ : intercept and $R^{2}$ : squared correlation coefficient.

By replacing $\eta_{\text {trm }}\left(R_{\mathrm{v}}<0.25\right)=1$ (TR1 in Table 4$)$ or continuing $\eta_{\text {trm }}$ for $R_{\mathrm{v}}<0.25$ (TR in Table 4 , as well as Fig. 11) a correction for nearly $85 \%$ of the collected data was possible. Both approaches TR and TR1 did remarkably decrease the slope, however, they also decreased $R^{2}$. As the slopes for TR were steeper than for TR1, we would suggest to use TR for the transmission regime. Moreover, this would also avoid any sharp steps for $\eta_{\text {trm }}$ when decreasing $R_{\mathrm{V}}$ below 0.25 . However, data with $0.5>R_{\mathrm{V}}>0.8$ and $\theta_{\mathrm{S}}>60^{\circ}$ (green crosses in Fig. 11, which was the regime where $\eta_{\text {asp }}$ shows an unphysical behavior) still had a higher slope $(m=1.55$ for $\mathrm{LWC}_{\text {geo }}$ and $m=1.52$ for $\mathrm{LWC}_{\mathrm{PDF}, 2 \mu \mathrm{m}}$, not shown). Applying the ASP09TR correction moved those points closer to the one to one line and changed the slopes to around 1.1 for $\mathrm{LWC}_{\mathrm{geo}}$ as well as $\mathrm{LWC}_{\mathrm{PDF}, a \mu \mathrm{m}}$, and $R^{2}$ were comparable to the uncorrected data. For the horizontal sampling, slopes and intercepts were similar while the $R^{2}$ was even around 0.5 . For the downward sampling, slopes were similar but intercepts were higher and $R^{2}$ lower, which would mean that the applied corrections did not have the same effect as for horizontal sampling.

We could think of different explanations for that: first, as the correlation for downward sampling was already worse for uncorrected sampling and still persisted the corrections for particle losses; it could be that the FM-100 was more protected by the building due to its tilting and therefore the cloud sampling was less representative than for the first period. Second, for the same reason, it could be that the wind field as measured by the ultrasonic anemometer was less representative for the wind field around the FM-100 inlet. Consequently, the corrections would not be as successful for the downward sampling as for the horizontal sampling. Therefore, it is difficult to evaluate whether the corrections for particle losses were appropriate for the downward sampling or whether the data themselves were worse for the downward sampling. Further studies with the PVM-100, the FM100 and the ultrasonic anemometer mounted in close vicinity would be needed to further evaluate the performance of the particle loss corrections.

Although the effect of the particle losses on the LWC were considerable, the corrections did not change the relation between $N_{\text {cr }}$ and $N_{\mathrm{FM}}^{\text {eff }}$ (total droplet number concentration deduced from the FM-100 with $D_{\text {geo }}$ and corrections for particle loss) in a way that it was measurable by means of geometric mean regressions or $R^{2}$ (see Fig. 12). Larger droplets were mainly affected by particle loss calculations, 


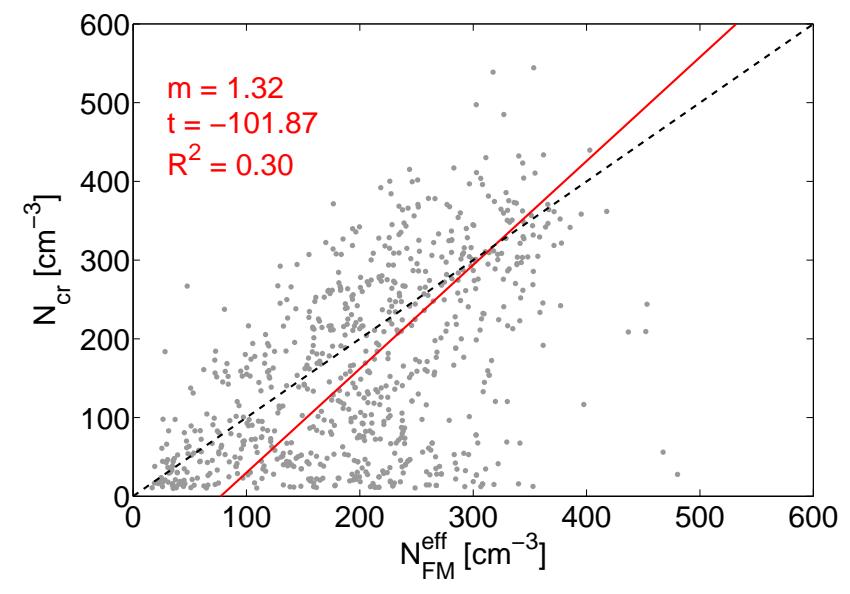

Fig. 12. Number concentrations of cloud residuals $\left(N_{\mathrm{cr}}\right)$ deduced from two SMPS systems and corrected for particle losses as described in Sect. 2.2.4 versus cloud droplet number concentration measured by the FM-100 corrected for particle losses using ASP09TR - see Table 3 - for all data $\left(N_{\mathrm{FM}}^{\mathrm{eff}}\right)$.

as they were too heavy to follow the gas stream lines. Obviously, these particles play a minor role for $N_{\mathrm{FM}}$, which would mean that the ambient amount of larger droplets during CLACE 2010 was small. Nevertheless, these larger droplets determine the $\mathrm{LWC}$, which is why the $\mathrm{LWC}_{\mathrm{FM}}$ was very sensitive to particle loss corrections. To summarize, if the FM100 is used to study LWC rather than $N$, we strongly recommend making particle loss calculations.

\subsection{Recommendation for future deployments of the FM-100}

Based on the analysis presented here we have the following recommendations for future installations of the FM-100:

1. A careful analysis of the sampling system revealed that there is a considerable error in the $\mathrm{LWC}_{\mathrm{FM}}$ arising from the measurement principle. A possibility of reducing the errors from Mie scattering is to choose the 40 thresholds in such a way that they correspond better to the Mie curve, similar to what was done by Gonser et al. (2011). This is already a common procedure for other optical particle counters (e.g. Pinnick et al., 1981; Dye and Baumgardner, 1984) but has only been used by Gonser et al. (2011) when measuring with the FM-100. Additionally, the signal should be redistributed using probability density functions as proposed here. However, one needs to know the instrumental response of the FM-100 in detail as they differ between the individual instruments (e.g. range of detected scattering angles or laser wavelength). We therefore recommend to use a Mie band deduced from a set of scattering angles rather than a single Mie curve. Moreover, this needs to be done before the installation of the FM-100, as the channel thresholds can no longer be changed afterwards.

2. Additionally, not all droplets of the ambient air reach the sampling device due to aspiration and transmission losses. Moreover, a considerable amount of particles gets lost within the instrument before reaching the sampling region. While isoaxial sampling can be more or less achieved by mounting the FM-100 on a turnable platform, isokinetical sampling cannot be achieved with a pump running at constant speed. We therefore recommend doing loss calculations for the droplet measurements even if the instrument can be turned into the wind direction. In order to perform such calculations, use of an ultrasonic anemometer close by the FM-100 is crucial as well as a reference for the LWC such as a PVM-100.

\section{Conclusions}

In this work, the accuracy of the commercially available fog monitor FM-100 was investigated by focusing on the effect of Mie scattering on droplet sizing and on particle losses occurring during the operation. The conclusions based on the analysis of both uncertainties individually as well as the CLACE 2010 data set are the following:

1. Concerning the sizing procedure, the default (manufacturer's) channel selection is sufficient for the determination of the total droplet number concentration $\left(N_{\mathrm{FM}}\right)$ or the total liquid water content $\left(\mathrm{LWC}_{\mathrm{FM}}\right)$. For a maximal error estimate of the $\mathrm{LWC}$, the choice would be $\mathrm{LWC}_{\text {geo }}$ as an appropriate estimate of the $\mathrm{LWC}$ and $\mathrm{LWC}_{\min }$ and $\mathrm{LWC}_{\max }$ as the maximal error assumption. Moreover, we showed that a redistribution of the measured scattering signal using a stochastic approach (based on probability density functions) leads to a more appropriate reproduction of the ambient droplet size distributions than conventional methods.

2. Depending on sampling angles and wind speeds, particle losses due to sampling losses and losses within the FM-100 can be as high as $100 \%$. Consequently, particle loss corrections (in the ASP09TR version, see Table 3 for details) for the FM-100 are needed if the focus of the study is the $\mathrm{LWC}_{\mathrm{FM}}$ or fluxes calculated based on the $\mathrm{LWC}_{\mathrm{FM}}$.

Future studies should also explore whether a passive openpath droplet size spectrometer, e.g. as used on aircrafts, would yield better results even at the low wind speeds typically found near the ground surface under foggy conditions. 


\section{Appendix A}

\section{Formulas used for particle losses}

\section{A1 Aspiration efficiency}

For the moving air regime, we use the formulas which were based on a literature survey and experiments done by Hangal and Willeke (1990a,b). For a sampling angle $\theta_{\mathrm{s}}$ between $0^{\circ}$ and $60^{\circ}\left(60^{\circ}\right.$ included $)$ they deduced:

$\eta_{\text {asp,move }}(D)=1+\left[\left(\frac{U_{0}}{U}\right) \cos \theta_{\mathrm{s}}-1\right] f$,

where

$$
\begin{aligned}
f= & \frac{1-\left[1+\left(2+0.617 \frac{U}{U_{0}}\right) S t k^{\prime}\right]^{-1}}{1-\left[1+2.617 S t k^{\prime}\right]^{-1}} \\
& \times\left\{1-\left[1+0.55 S t k^{\prime} \exp \left(0.25 S t k^{\prime}\right)\right]^{-1}\right\} .
\end{aligned}
$$

With Stk the Stokes number of the sampling inlet (see Brockmann, 2011, for detailed information) and $S t k^{\prime}=S t k \exp \left(0.022 \theta_{\mathrm{s}}\right)$. This equation is valid for $0.01 \leq$ Stk $\leq 6$ and $0.5 \leq R_{\mathrm{v}} \leq 2$.

For sampling angles from $61^{\circ}$ to $90^{\circ}$, Hangal and Willeke (1990a) suggested (based on measurements with $90^{\circ}$ sampling angle):

$\eta_{\text {asp,move }}(D)=1+\left(R_{\mathrm{v}} \cos \theta_{\mathrm{S}}-1\right)\left(3 S t k^{\sqrt{R_{\mathrm{v}}}}\right)$,

for $0.003 \leq S t k \leq 0.2$ and $R_{\mathrm{v}} \geq 1.25$. However, in more recent publications the validity range was extended to $0.02 \leq$ Stk $\leq 0.2$ and $0.5 \leq R_{\mathrm{V}} \leq 2$ (von der Weiden et al., 2009; Brockmann, 2011).

For the calm air regime, we decided to use the empirical equation deduced by Grinshpun et al. (1993) based on several experiments, as the one by Su and Vincent $(2004,2005)$ is only applicable for aspiration efficiencies larger than 0.75 and the alternative one by Dunnett and Wen (2002) was numerically deduced for larger particle diameters $(40 \mu \mathrm{m}$ to $110 \mu \mathrm{m})$ :

$\eta_{\text {asp,calm }}(D)=\frac{V_{\mathrm{ts}}}{U} \cos \phi+\exp \left(\frac{4 S t k^{1+\sqrt{V_{\mathrm{ts}} / U}}}{1+2 S t k}\right)$,

where $V_{\mathrm{ts}}$ is the terminal settling velocity (see Brockmann, 2011 for detailed information), and $\phi$ is the zenith angle of the inlet $\left(\phi=90^{\circ}\right.$ for horizontal sampling). The first term describes gravitational settling of particles dependent on the inlet orientation and the second term addresses inertial and gravitational losses independent of inlet orientation. This equation is valid for $10^{-3} \leq V_{\mathrm{ts}} / U \leq 1$ and $0.001 \leq S t k \leq 100$ for angles $0^{\circ} \leq \phi \leq 90^{\circ}$. For $V_{\mathrm{ts}} / U<10^{-3}$ we set $\eta_{\text {asp }}(D)=0$ in the calm air regime as we then assume that the particles are small enough that they can follow the stream lines. In the literature the slow moving air regime is not clearly defined (von der Weiden et al., 2009). So we choose the boundaries such that they fill the gap between calm air and slow moving air $\left(0.5 \mathrm{~m} \mathrm{~s}^{-1} \leq U_{0}\right.$ and $\left.R_{\mathrm{v}} \leq 0.5\right)$. The formulas used are based on the work by Grinshpun et al. $(1993,1994)$ :

$$
\begin{aligned}
& \eta_{\text {asp }}(D)=\eta_{\text {asp } \text { move }}(D)(1+\delta)^{0.5} f_{\text {move }}+\eta_{\text {asp }, \text { alm }}(D) f_{\text {calm }}, \\
& f_{\text {move }}=\exp \left(-\frac{V_{\mathrm{ts}}}{U_{0}}\right) \\
& f_{\text {calm }}=1-\exp \left(-\frac{V_{\mathrm{ts}}}{U_{0}}\right) \\
& \delta=\frac{V_{\mathrm{ts}}}{U_{0}}\left[\frac{V_{\mathrm{ts}}}{U_{0}}+2 \cos \left(\theta_{\mathrm{s}}+\phi\right)\right]
\end{aligned}
$$

for $10^{-3} \leq V_{\mathrm{ts}} / U \leq 1$ and $10^{-3} \leq$ Stk $\leq 100,10^{-3} \leq R_{\mathrm{v}} \leq 10$ with zenith angle $0^{\circ} \leq \phi \leq 90^{\circ}$.

\section{A2 Transmission efficiency}

Hangal and Willeke (1990b) proposed that the transmission efficiency consist of an inertial and a gravitational part. However, von der Weiden et al. (2009) suggest that the gravitational effect is better described as part of the transport efficiency. Hence, we only take into account the inertial effect with the following formula in the validity range of $0.02 \leq S t k \leq 4,0.25 \leq R_{\mathrm{v}} \leq 4$, and $0^{\circ} \leq \theta_{\mathrm{s}} \leq 90^{\circ}$ :

$\eta_{\mathrm{trm}}(D)=\exp \left[-75\left(I_{\mathrm{v}}+I_{\mathrm{w}}\right)^{2}\right]$,

where $I_{\mathrm{v}}$ are the losses in the vena contracta. The vena contracta only forms when the sampling conditions are superisokinetic:

$I_{\mathrm{v}}=0.09\left(\operatorname{Stk} \frac{U-U_{0}}{U_{0}} \cos \theta_{\mathrm{s}}\right)^{0.3}$,

for $0.25 \leq R_{\mathrm{v}} \leq 1$ otherwise $I_{\mathrm{v}}=0 . I_{\mathrm{w}}$ are the losses from direct impaction to the wall:

$I_{\mathrm{w}}=S t k \sqrt{R_{\mathrm{v}}} \sin \left(\theta_{\mathrm{s}}+\alpha\right) \sin \left(\frac{\theta_{\mathrm{s}}+\alpha}{2}\right)$,

for $0.02 \leq S t k \leq 4$, and $0.25 \leq R_{\mathrm{v}} \leq 4$, where

$\alpha=12\left[\left(1-\frac{\theta_{\mathrm{s}}}{90^{\circ}}\right)-\exp \left(-\theta_{\mathrm{s}}\right)\right]$.

\section{A3 Transport losses}

The FM-100 consists of a two-part tubing system: a contraction zone and a wind tunnel with constant diameter (Fig. 5). For the second part with constant diameter there are two contributions to the loss mechanisms: 
- Sedimentation $\eta_{\text {grav }}$

Particles deposit due to gravitational forces on the lower wall of the FM-100 wind tunnel. There are different correction formulas available, depending on the flow conditions and the tube orientation. As the flow in the wind tunnel of the FM-100 is turbulent (Reynolds number, $R e \approx 23000$ for CLACE $2010, R e \approx 21000$ at sea level pressure and $25^{\circ} \mathrm{C}$ ), we use the formulas presented by Schwendiman et al. (1975):

$$
\eta_{\text {grav }}(D)=\exp \left(-\frac{4 V_{\mathrm{ts}} L_{\mathrm{w}} \cos \theta}{\operatorname{TAS} d_{o} \pi}\right),
$$

where $L_{\mathrm{w}}$ is the length of the wind tunnel (till the laser region), $d_{o}$ is the diameter of the wind tunnel, True Air Speed TAS $=13.15 \mathrm{~m} \mathrm{~s}^{-1}$, which is the mean value of the flow velocity in the wind tunnel measured by the pitot tube, and $\theta$ angle of inlet inclination $\left(=0^{\circ}\right.$ for horizontal flow). This equation is valid for $\frac{V_{\mathrm{ts}} \sin \theta}{\mathrm{TAS}} \ll 1$.

\section{- Turbulent inertial deposition $\eta_{\text {turb }}$}

Depending on the size of the particle there are two different regimes of how particles are "thrown" to the tube wall by eddies: the turbulent diffusion-eddy impaction and the particle inertia-moderated regime (Brockmann, 2011). For the first one, particle deposition increases with particle size as their inertia gets larger. For the second regime, the particles are so large, that their trajectory does no longer perfectly follow that of a gas molecule that does not suffer from inertial effects, so particle losses increase slightly with size. There are different corrections suggested in the literature. Here, we use a correction based on Liu and Agarwal (1974) who introduced the dimensionless turbulent velocity $V_{+}$and the dimensionless particle relaxation time $\tau_{+}$in order to describe the transition between the two regimes:

$\eta_{\mathrm{turb}}(D)=\exp \left(-\frac{4 V_{\mathrm{t}} L_{\mathrm{w}}}{\operatorname{TAS} d_{o} \pi}\right)$,

where $V_{\mathrm{t}}$ is the deposition velocity for turbulent inertial deposition, with

$$
\begin{aligned}
\tau_{+} & =0.0395 \text { Stk } R e^{1 / 8}, \\
V_{\mathrm{t}} & =\frac{V_{+} \mathrm{TAS}}{5.03 \operatorname{Re}^{1 / 8}} .
\end{aligned}
$$

For the moderate particle inertia regime $\left(\tau_{+} \geq 12.9\right)$, we use a constant $V_{+}=0.1$, and for the turbulent diffusion eddy $\left(\tau_{+} \leq 12.9\right)$ the turbulent velocity is estimated as $V_{+}=0.0006 \tau_{+}^{2}$.
For the contraction part, there is only one formula available: Inertial loss in a contraction $\eta_{\text {cont }}$

In the contraction part droplets are accelerated due to the decreasing diameter of the transport tubing. Larger particles could eventually not follow the changes in the trajectories resulting in wall impaction due to inertia. Muyshondt et al. (1996) experimentally derived a formula for the inertial losses in the contraction part of a transport tubing:

$$
\eta_{\text {cont }}(D)=1-\frac{1}{1+2\left[\frac{S t k\left(1-\frac{A_{o}}{A_{\mathrm{i}}}\right)}{3.14 \exp \left(-0.0185 \theta_{\text {cont }}\right)}\right]^{1.24}},
$$

where $A_{o}$ is the cross sectional area of the wind tunnel, $A_{\mathrm{i}}$ cross sectional area of the inlet, and $\theta_{\text {cont }}$ is the contraction half angle of the contraction part. The formula is valid for $0.001 \leq \operatorname{Stk}\left(1-A_{o} / A_{\mathrm{i}}\right) \leq 100$, and $12^{\circ} \leq \theta_{\text {cont }} \leq 90^{\circ}$. Unfortunately, the $\theta_{\text {cont }}$ of the contraction part of the FM-100 is only $6^{\circ}$. As the losses get smaller with smaller $\theta_{\text {cont }}$ within the validity range, we still use this formula in order to get an upper estimate for the losses, and hence we expect the true losses to be a bit smaller than this estimate.

The contraction part is longer than the second part with constant diameter. We therefore assume that we cannot ignore the inertial losses due to turbulence $\left(\eta_{\text {turb,cont }}\right)$ as well as the gravitational losses $\left(\eta_{\text {grav,cont }}\right)$. We therefore determine those efficiencies iteratively using the Eqs. (A13)-(A16).

\begin{tabular}{|c|c|}
\hline$A_{i}$ & Cross sectional area of the inlet \\
\hline$A_{o}$ & Cross sectional area of the wind tunnel \\
\hline$b_{\text {low }}$ & $\begin{array}{l}\text { Lower margin for the pulse amplitude of a } \\
\text { channel }\end{array}$ \\
\hline$b_{\text {up }}$ & $\begin{array}{l}\text { Upper margin for the pulse amplitude of a } \\
\text { channel }\end{array}$ \\
\hline $\mathrm{CWC}$ & Condensed Water Content \\
\hline$D$ & Droplet diameter \\
\hline$D_{i}$ & Geometric mean diameter of channel $i$ \\
\hline$D_{\text {low }}$ & Diameter for which Mie band $=b_{\text {low }}$ \\
\hline$D_{n}$ & $\begin{array}{l}\text { Median diameter of the log normal droplet } \\
\text { size distribution }\end{array}$ \\
\hline & Diameter for which Mie band $=b_{\text {up }}$ \\
\hline & Inlet diameter \\
\hline & Diameter of the wind tunnel \\
\hline
\end{tabular}

\section{Appendix B}

\section{List of symobls}

\section{B1 Latin symbols}


LWC Liquid Water Content (see Sect. B3 for subscripts used and Sect. B4 for superscripts used)

LWC $_{\mathrm{FM}} \quad$ Liquid Water Content measured by FM-100

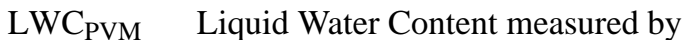
PVM-100

$I_{\mathrm{V}}$

$I_{\mathrm{W}}$

$i_{\max }$

$L_{k}$

$L_{\mathrm{w}}$

$N$

$N_{\mathrm{FM}}$

$N_{\text {cr }}$

$N_{\text {int }}$

$N_{\text {tot }}$

$N_{\mathrm{t}, \log }$

$n$

$n^{*}(D)$

$n_{\log }(D)$

$n_{i}$

$\operatorname{PDF}_{i}(D)$

$\operatorname{PDFN}_{i}(D)$ Normalized discrete probability density

Re Reynolds number

RH Relative humidity

$R_{\mathrm{V}} \quad$ Velocity ratio

Stk Stokes number

TAS True Air Speed measured by the pitot tube

TWC

$U$

$U_{0}$

VWC

$V_{\mathrm{ts}}$

$V_{\mathrm{t}}$

$V^{+}$ function of channel $i$

Particle losses from direct impaction to the wall with the FM-100

Contributions of the loss mechanism $k$ to the overall losses ( $k=$ asp, trm, tsp)

Length of the wind tunnel

Droplet number concentration (Sect. B4 for superscripts used)

$\left(N_{\text {tot-int }}\right)$

activated aerosol number

the interstitial inlet

number concentration measured with the SMPS at the total aerosol inlet

log normal droplet size distribution

Droplet size distribution (see Sect. B3 for subscripts)

bin width $\Delta D=0.02 \mu \mathrm{m}$

Log normal size distribution

Droplet number concentration per channel

measured by FM-100

Discrete probability density function of

Total Cloud Water

Sampling speed (=velocity at the inlet)

Surrounding wind speed

Water Content of the Vapor phase

Terminal settling velocity

Deposition velocity for turbulent inertial deposition

Dimensionless deposition velocity

\section{B2 Greek symbols}

\begin{tabular}{|c|c|}
\hline$\Delta D$ & Bin size used for the stochastic approach \\
\hline$\Delta D_{\mathrm{R}}$ & $\begin{array}{l}\text { Resolution used for redistributing the } \\
\text { channels in the stochastic approach }\end{array}$ \\
\hline$\phi$ & $\begin{array}{l}\text { Zenith angle of the inlet (instrument } \\
\text { positioning) }\end{array}$ \\
\hline$\rho_{\mathrm{H}_{2} \mathrm{O}}$ & Density of water \\
\hline$\eta_{\text {asp }}$ & $\begin{array}{l}\text { Aspiration efficiency ( } \eta_{\text {asp,calm }} \text { for the } \\
\text { calm regime and } \eta_{\text {asp,move }} \text { for the moving } \\
\text { air regime) }\end{array}$ \\
\hline$\eta_{\text {cont }}$ & $\begin{array}{l}\text { Efficiency describing inertial losses in a } \\
\text { contraction }\end{array}$ \\
\hline$\eta_{\text {grav }}$ & $\begin{array}{l}\text { Efficiency describing losses through } \\
\text { sedimentation }\end{array}$ \\
\hline$\eta_{\text {grav,cont }}$ & $\begin{array}{l}\text { Efficiency describing gravitational losses } \\
\text { in a contraction }\end{array}$ \\
\hline$\eta_{\mathrm{smp}}$ & Sampling efficiency \\
\hline$\eta_{\text {tot }}$ & Inlet efficiency \\
\hline$\eta_{\text {trm }}$ & Transmission efficiency \\
\hline$\eta_{\text {tsp }}$ & Transport efficiency \\
\hline$\eta_{\text {turb }}$ & $\begin{array}{l}\text { Efficiency describing losses through } \\
\text { turbulent inertial deposition }\end{array}$ \\
\hline$\eta_{\text {turb,cont }}$ & $\begin{array}{l}\text { Efficiency describing inertial losses due } \\
\text { to turbulences in a contraction }\end{array}$ \\
\hline$\lambda$ & Laser wavelength \\
\hline$\theta$ & $\begin{array}{l}\text { Angle of inlet inclination (instrument } \\
\text { positioning) }\end{array}$ \\
\hline$\theta_{\text {cont }}$ & Contraction half angle \\
\hline$\theta_{\mathrm{s}}$ & Sampling angle \\
\hline$\sigma_{\log }$ & $\begin{array}{l}\text { Logarithmic width of the log normal } \\
\text { droplet size distribution }\end{array}$ \\
\hline$\tau_{+}$ & Dimensionless particle relaxation time \\
\hline
\end{tabular}

\section{B3 Subscripts used for $D, n$ and LWC}

$\mathrm{dft}$

Used for values deduced from the geometric mean diameter of the default channels

geo Used for values deduced from the geometric mean diameter of the Mie channels

$\max \quad$ Used for values deduced from the maximum diameter of the Mie channels

$\min \quad$ Used for values deduced from the minimum diameter of the Mie channels

PDF, $a \mu \mathrm{m} \quad$ Used for values deduced from the stochastic approach with bin size $\Delta D=\mathrm{a} \mu \mathrm{m}$

\section{B4 Superscripts used for $N$ and LWC}

eff 
Acknowledgements. We thank the International Foundation High Altitude Research Stations Jungfraujoch and Gornergrat (HFSJG) for the opportunity to perform experiments on the Jungfraujoch. This work was supported by MeteoSwiss within the Global Atmosphere Watch programme of the World Meteorological Organization. We would like to thank Swiss Meteorological Institute (MeteoSwiss) for providing meteorological measurements, Berko Sierau and Ulrike Lohmann (IAC-ETHZ) for loaning us their FM-100, Darrel Baumgardner for fruitful discussions on Mie scattering, Bernd Pinzer for interesting discussions on probability density functions and Nina Buchmann for comments on this manuscript.

Edited by: S. Malinowski

\section{References}

Albrecht, B. A.: Aerosols, Cloud Microphysics, and Fractional Cloudiness, Science, 245, 1227-1230, 1989.

Allan, J. D., Baumgardner, D., Raga, G. B., Mayol-Bracero, O. L., Morales-García, F., García-García, F., Montero-Martínez, G., Borrmann, S., Schneider, J., Mertes, S., Walter, S., Gysel, M., Dusek, U., Frank, G. P., and Krämer, M.: Clouds and aerosols in Puerto Rico - a new evaluation, Atmos. Chem. Phys., 8, 12931309, doi:10.5194/acp-8-1293-2008, 2008.

Arends, B. G., Kos, G. P. A., Maser, R., Schell, D., Wobrock, W., Winkler, P., Ogren, J. A., Noone, K. J., Hallberg, A., Svenningsson, I. B., Wiedensohler, A., Hansson, H. C., Berner, A., Solly, I., and Kruisz, C.: Microphysics of clouds at Kleiner Feldberg, J. Atmos. Chem., 19, 59-85, doi:10.1007/BF00696583, 1994.

Baltensperger, U., Schwikowski, M., Jost, D., Nyeki, S., Gäggeler, H., and Poulidas, O.: Scavenging of atmospheric constituents in mixed phase clouds at the high-alpine site Jungfraujoch Part I: Basic concept and aerosol scavenging by clouds, Atmos. Environ., 32, 3975-3983, doi:10.1016/S1352-2310(98)00051-X, 1998.

Baumgardner, D.: An analysis and comparison of five water droplet measuring instruments, J. Appl. Meteorol., 22, 891-910, 1983.

Baumgardner, D., Dye, J. E., Gandrud, B. W., and Knollenberg, R. G.: The forward scattering spectrometer probe (FSSP-300) during the airborne arctic stratospheric expedition, J. Geophys. Res., 97, 8035-8046, 1992.

Baumgardner, D., Gayet, J. F., Gerber, H., Korolev, A., and Twohy, C.: CLOUDS - Measurement Techniques In Situ, in: Encyclopedia of Atmospheric Sciences, Academic Press, 489-498, 2003.

Baumgardner, D., Kok, G., and Chen, P.: Multimodal Size Distributions in Fog: Cloud Microphysics or Measurement Artifact?, in: 5th International Conference on Fog, Fog Collection and Dew, held 25-30 July 2010, Münster, Germany, vol. 1, p. 73, 2010.

Baumgardner, D., Brenguier, J., Bucholtz, A., Coe, H., DeMott, P., Garrett, T., Gayet, J., Hermann, M., Heymsfield, A., Korolev, A., Krämer, M., Petzold, A., Strapp, W., Pilewskie, P., Taylor, J., Twohy, C., Wendisch, M., Bachalo, W., and Chuang, P.: Airborne instruments to measure atmospheric aerosol particles, clouds and radiation: A cook's tour of mature and emerging technology, Atmos. Res., 102, 10-29, doi:10.1016/j.atmosres.2011.06.021, 2011.

Beiderwieden, E.: Fogwater fluxes above a subtropical montane cloud forest, Phd thesis, Westfälische Wilhelms-Universität
Münster, 2007.

Beiderwieden, E., Wolff, V., Hsia, Y., and Klemm, O.: It goes both ways: measurements of simultaneous evapotranspiration and fog droplet deposition at a montane cloud forest, Hydrol. Process., 4189, 4181-4189, 2008.

Bennartz, R., Fan, J., Rausch, J., Leung, L. R., and Heidinger, A. K.: Pollution from China increases cloud droplet number, suppresses rain over the East China Sea, Geophys. Res. Lett., 38, L09704, doi:10.1029/2011GL047235, 2011.

Bohren, C. F. and Huffman, D. R.: Absorption and Scattering of Light by Small Particles: the Interference Structure, vol. 29, John Wiley \& Sons, 1983.

Brockmann, J. E.: Aerosol Transport in Sampling Lines and Inlets, in: Aerosol Measurement: Principles, Techniques, and Applications, chap. 6, 3rd Edn., edited by: Kulkarni, P., Baron, P., and Willeke, K., John Wiley \& Sons, 69-105, 2011.

Bruijnzeel, L. A. S., Eugster, W., and Burkard, R.: Fog as a Hydrologic Input, in: Encyclopedia of Hydrological Sciences, edited by: Anderson, M. G., John Wiley \& Sons, Ltd., 559-582, 2005.

Burkard, R., Eugster, W., Wrzesinsky, T., and Klemm, O.: Vertical divergence of fogwater fluxes above a spruce forest, Atmos. Res., 64, 133-145, doi:10.1016/S0169-8095(02)00086-8, 2002.

Burkard, R. T.: Fogwater Flux Measurements Above Different Vegetation Canopies, Phd thesis, Universität Bern, 2003.

Chuang, P. Y., Saw, E. W., Small, J. D., Shaw, R. A., Sipperley, C. M., Payne, G. A., and Bachalo, W. D.: Airborne Phase Doppler Interferometry for Cloud Microphysical Measurements, Aerosol Sci. Tech., 42, 685-703, doi:10.1080/02786820802232956, 2008.

Collaud Coen, M., Weingartner, E., Nyeki, S., Cozic, J., Henning, S., Verheggen, B., Gehrig, R., and Baltensperger, U.: Long-term trend analysis of aerosol variables at the highalpine site Jungfraujoch, J. Geophys. Res., 112, D13213, doi:10.1029/2006JD007995, 2007.

Connolly, P. J., Flynn, M. J., Ulanowski, Z., Choularton, T. W., Gallagher, M. W., and Bower, K. N.: Calibration of the Cloud Particle Imager Probes Using Calibration Beads and Ice Crystal Analogs: The Depth of Field, J. Atmos. Oceanic Tech., 24, 1860-1879, doi:10.1175/JTECH2096.1, 2007.

Cozic, J., Verheggen, B., Weingartner, E., Crosier, J., Bower, K. N., Flynn, M., Coe, H., Henning, S., Steinbacher, M., Henne, S., Collaud Coen, M., Petzold, A., and Baltensperger, U.: Chemical composition of free tropospheric aerosol for PM1 and coarse mode at the high alpine site Jungfraujoch, Atmos. Chem. Phys., 8, 407-423, doi:10.5194/acp-8-407-2008, 2008.

Droplet Measurement Technologies: Fog Monitor Model FM-100 Operator Manual (DOC-0088 Revision H), published by Droplet Measurement Technologies, Inc., Boulder, USA, 2011.

Dunnett, S. and Wen, X.: A numerical study of the sampling efficiency of a tube sampler operating in calm air facing both vertically upwards and downwards, J. Aerosol Sci., 33, 1653-1665, doi:10.1016/S0021-8502(02)00118-0, 2002.

Durham, M. D. and Lundgren, D. A.: Evaluation of aerosol aspiration efficiency as a function of stokes number, velocity ratio and nozzle angle, J. Aerosol Sci., 11, 179-188, doi:10.1016/00218502(80)90033-6, 1980.

Dye, J. E. and Baumgardner, D.: Evaluation of the forward scattering spectrometer probe, I - Electronic and optical studies, J. Atmos. Ocean. Tech., 1, 329-344, 1984. 
Eugster, W. and Plüss, P.: A fault-tolerant eddy covariance system for measuring $\mathrm{CH}_{4}$ fluxes, Agr. Forest. Meteorol., 150, 841-851, doi:10.1016/j.agrformet.2009.12.008, 2010.

Eugster, W., Burkard, R., Holwerda, F., Scatena, F., and Bruijnzeel, L.: Characteristics of fog and fogwater fluxes in a Puerto Rican elfin cloud forest, Agr. Forest. Meteorol., 139, 288-306, doi:10.1016/j.agrformet.2006.07.008, 2006.

Frumau, K. F. A., Burkard, R., Schmid, S., Bruijnzeel, L. A. S., Tobón, C., and Calvo-Alvarado, J. C.: A comparison of the performance of three types of passive fog gauges under conditions of wind-driven fog and precipitation, Hydrol. Process., 25, 374383, doi:10.1002/hyp.7884, 2011.

Fuzzi, S., Orsi, G., and Mariotti, M.: Wet deposition due to fog in the Po Valley, Italy, J. Atmos. Chem., 3, 289-296, doi:10.1007/BF00210501, 1985.

Gerber, H.: Direct measurement of suspended particulate volume concentration and far-infrared extinction coefficient with a laserdiffraction instrument, Appl. Optics, 30, 4824-4831, 1991.

Gonser, S. G., Klemm, O., Griessbaum, F., Chang, S.-C., Chu, H.S., and Hsia, Y.-J.: The Relation Between Humidity and Liquid Water Content in Fog: An Experimental Approach, Pure Appl. Geophys., 169, 821-833, doi:10.1007/s00024-011-0270$\mathrm{x}, 2011$.

Grinshpun, S., Willeke, K., and Kalatoor, S.: A general equation for aerosol aspiration by thin-walled sampling probes in calm and moving air, Atmos. Environ. A-Gen., 27, 1459-1470, 1993.

Grinshpun, S., Chang, C., Nevalainen, A., and Willeke, K.: Inlet characteristics of bioaerosol samplers, J. Aerosol Sci., 25, 15031522, 1994.

Gunn, R. and Philips, B. B.: A experimental investigation of the effect of air pollution on the initiation of rain, J. Meteorol., 14, 272-280, 1957.

Hangal, S. and Willeke, K.: Aspiration efficiency: unified model for all forward sampling angles, Environ. Sci. Technol., 24, 688691, doi:10.1021/es00075a012, 1990a.

Hangal, S. and Willeke, K.: Overall efficiency of tubular inlets sampling at $0-90{ }^{\circ}$ from horizontal aerosol flows, Atmos. Environ. A-Gen., 24, 2379-2386, doi:10.1016/0960-1686(90)90330P, 1990b.

Henning, S., Weingartner, E., Schmidt, S., Wendisch, M., Gaggeler, H. W., and Baltensperger, U.: Size-dependent aerosol activation at the high-alpine site Jungfraujoch $(3580 \mathrm{~m}$ asl), Tellus B, 54, 82-95, 2002.

Holwerda, F., Burkard, R., Eugster, W., Scatena, F. N., Meesters, A. G. C., and Bruijnzeel, L. A.: Estimating fog deposition at a Puerto Rican elfin cloud forest site: comparison of the water budget and eddy covariance methods, Hydrol. Process., 20, 26692692, doi:10.1002/hyp.6065, 2006.

Jaenicke, R. and Hanusch, T.: Simulation of the optical-particle counter forward scattering spectrometer probe-100 (fssp-100) consequences for size distribution measurements, Aerosol Sci. Tech., 18, 309-322, doi:10.1080/02786829308959607, 1993.

Kamphus, M., Ettner-Mahl, M., Klimach, T., Drewnick, F., Keller, L., Cziczo, D. J., Mertes, S., Borrmann, S., and Curtius, J.: Chemical composition of ambient aerosol, ice residues and cloud droplet residues in mixed-phase clouds: single particle analysis during the Cloud and Aerosol Characterization Experiment (CLACE 6), Atmos. Chem. Phys., 10, 8077-8095, doi:10.5194/acp-10-8077-2010, 2010.
Ketterer, C. : Investigation of the planetary boundary layer using remote sensing and in-situ measurements at the Kleine Scheidegg and at the Jungfraujoch, Masterthesis, available at http://www.climatestudies.unibe.ch/students/personalpage_en. html?id=75, University of Berne, Faculty of Sciences, Berne, 2011.

Knollenberg, R. G.: Techniques for Probing Cloud Microstructure, in: Clouds, Their Formation, Optical Properties and Effects, edited by: Hobbs, P. V. and Deepak, A., Academic Press, New York, NY, USA, 15-92, 1981.

Kokhanovsky, A. and Rozanov, V. V.: Droplet vertical sizing in warm clouds using passive optical measurements from a satellite, Atmos. Meas. Tech., 5, 517-528, doi:10.5194/amt-5-517-2012, 2012.

Kowalski, A.: Near-surface fluxes of cloud water evolve vertically, Q. J. Roy. Meteorol. Soc., 125, 2663-2684, 1999.

Kowalski, A., Anthoni, P., Vong, R., Delany, A., and Maclean, G.: Deployment and evaluation of a system for ground-based measurement of cloud liquid water turbulent fluxes, J. Atmos. Ocean. Tech., 14, 468-479, 1997.

Lance, S., Brock, C. A., Rogers, D., and Gordon, J. A.: Water droplet calibration of the Cloud Droplet Probe (CDP) and inflight performance in liquid, ice and mixed-phase clouds during ARCPAC, Atmos. Meas. Tech., 3, 1683-1706, doi:10.5194/amt3-1683-2010, 2010.

Liou, K.: An Introduction to Atmospheric Radiation, 2nd Edn., vol. 84 of International Geophysics Series, Academic Press, 2002.

Liu, B. and Agarwal, J.: Experimental observation of aerosol deposition in turbulent flow, J. Aerosol Sci., 5, 145-155, 1974.

Liu, D., Yang, J., Niu, S., and Li, Z.: On the Evolution and Structure of a Radiation Fog Event in Nanjing, Adv. Atmos. Sci., 28, 223237, doi:10.1007/s00376-010-0017-0, 2011.

Mätzler, C.: MATLAB Functions for Mie Scattering and Absorption Version 2, Tech. rep., University of Bern, Bern, 2002.

McFarquhar, G. M., Um, J., Freer, M., Baumgardner, D., Kok, G. L., and Mace, G.: Importance of small ice crystals to cirrus properties: Observations from the Tropical Warm Pool International Cloud Experiment (TWP-ICE), Geophys. Res. Lett., 34, L13803, doi:10.1029/2007GL029865, 2007.

Mertes, S., Verheggen, B., Walter, S., Connolly, P., Ebert, M., Schneider, J., Bower, K. N., Cozic, J., Weinbruch, S., Baltensperger, U., and Weingartner, E.: Counterflow virtual impactor based collection of small ice particles in mixed-phase clouds for the physico-chemical characterization of tropospheric ice nuclei: sampler description and first case study, Aerosol Sci. Tech., 41, 848-864, doi:10.1080/02786820701501881, 2007.

Mie, G.: Beiträge zur Optik trüber Medien, speziell kolloidaler Metallösungen, Ann. Phys.-Berlin, 330, 377-445, 1908.

Miles, N. L., Verlinde, J., and Clothiaux, E. E.: Cloud Droplet Size Distributions in Low-Level Stratiform Clouds, J. Atmos. Sci., 57, 295-311, doi:10.1175/15200469(2000)057<0295:CDSDIL>2.0.CO;2, 2000.

Muyshondt, A., McFarland, A. R., and Anand, N. K.: Deposition of aerosol particles in contraction fittings, Aerosol Sci. Tech., 24, 205-216, doi:10.1080/02786829608965364, 1996.

Niu, S., Lu, C., Liu, Y., Zhao, L., Lü, J., and Yang, J.: Analysis of the microphysical structure of heavy fog using a droplet spectrometer: a case study, Adv. Atmos. Sci., 27, 1259-1275, 
doi:10.1007/s00376-010-8192-6, 2010.

Pinnick, R. and Auvermann, H.: Response characteristics of Knollenberg light-scattering aerosol counters, J. Aerosol Sci., 10, 5574, 1979.

Pinnick, R., Garvey, D., and Duncan, L.: Calibration of Knollenberg FSSP light-scattering counters for measurement of cloud droplets, J. Appl. Meteorol., 20, 1049-1057, 1981.

Pruppacher, H. R. and Klett, J. D.: Microphysics of Clouds and Precipitation, Kluwer Academic Publishers, Dordrecht, 1997.

Rosenberg, P. D., Dean, A. R., Williams, P. I., Dorsey, J. R., Minikin, A., Pickering, M. A., and Petzold, A.: Particle sizing calibration with refractive index correction for light scattering optical particle counters and impacts upon PCASP and CDP data collected during the Fennec campaign, Atmos. Meas. Tech., 5, 1147-1163, doi:10.5194/amt-5-1147-2012, 2012.

Rosenfeld, D. and Lensky, I. M.: Satellite based insights into precipitation formation processes in continental and maritime convective clouds, B. Am. Meteorol. Soc., 79, 2457-2476, doi:10.1175/1520-0477(1998)079<2457:SBIIPF>2.0.CO;2, 1998.

Schmid, S., Burkard, R., Frumau, K., Tobon, C., Bruijnzeel, L., Siegwolf, R., and Eugster, W.: Using eddy covariance and stable isotope mass balance techniques to estimate fog water contributions to a Costa Rican cloud forest during the dry season, Hydrol. Process., 25, 429-437, doi:10.1002/hyp.7739, 2010.

Schwendiman, L., Stegen, G., and Glissmeyer, J.: Methods and aids for assessing particle losses in sampling lines, Tech. rep., Report BNWL- SA-5138, 1975.

Stevens, B. and Feingold, G.: Untangling aerosol effects on clouds and precipitation in a buffered system., Nature, 461, 607-13, doi:10.1038/nature08281, 2009.

$\mathrm{Su}$, W.-C. and Vincent, J. H.: Towards a general semiempirical model for the aspiration efficiencies of aerosol samplers in perfectly calm air, J. Aerosol Sci., 35, 1119-1134, doi:10.1016/j.jaerosci.2004.04.003, 2004.

Su, W.-C. and Vincent, J. H.: Corrigendum to "Towards a general semi-empirical model for the aspiration efficiencies of aerosol samplers in perfectly calm air", J. Aerosol Sci., 36, 1468, doi:10.1016/j.jaerosci.2005.07.003, 2005.
Targino, A. C., Coe, H., Cozic, J., Crosier, J., Crawford, I., Bower, K., Flynn, M., Gallagher, M., Allan, J., Verheggen, B., Weingartner, E., Baltensperger, U., and Choularton, T.: Influence of particle chemical composition on the phase of cold clouds at a high-alpine site in Switzerland, J. Geophys. Res., 114, D18206, doi:10.1029/2008JD011365, 2009.

Thalmann, E.: Ion fluxes from fog and rain to an agricultural and a forest ecosystem in Europe, Atmos. Res., 64, 147-158, doi:10.1016/S0169-8095(02)00087-X, 2002.

Twomey, S.: The influence of pollution on the shortwave albedo of clouds, J. Atmos. Sci., 34, 1149-1152, 1977.

Van de Hulst H., Light Scattering by Small Particles (Structure of Matter Series), Dover, New York, 1981.

Verheggen, B., Cozic, J., Weingartner, E., Bower, K., Mertes, S., Connolly, P., Gallagher, M., Flynn, M., Choularton, T., and Baltensperger, U.: Aerosol partitioning between the interstitial and the condensed phase in mixed-phase clouds, J. Geophys. Res., 112, D23202, doi:10.1029/2007JD008714, 2007.

von der Weiden, S.-L., Drewnick, F., and Borrmann, S.: Particle Loss Calculator - a new software tool for the assessment of the performance of aerosol inlet systems, Atmos. Meas. Tech., 2, 479-494, doi:10.5194/amt-2-479-2009, 2009.

Vong, R.: Eddy correlation measurements of size-dependent cloud droplet turbulent fluxes to complex terrain, Tellus B, 47, 331352, 1995.

Weingartner, E., Nyeki, S., and Baltensperger, U.: Seasonal and diurnal variation of aerosol size distributions $(10<D<750 \mathrm{~nm})$ at a high-alpine site (Jungfraujoch $3580 \mathrm{~m}$ asl), J. Geophys. Res., 104, 26809-26820, doi:10.1029/1999JD900170, 1999.

Westbeld, A., Klemm, O., Grießbaum, F., Sträter, E., Larrain, H., Osses, P., and Cereceda, P.: Fog deposition to a Tillandsia carpet in the Atacama Desert, Ann. Geophys., 27, 3571-3576, doi:10.5194/angeo-27-3571-2009, 2009.

Wrzesinsky, T.: Summertime fog chemistry at a mountainous site in central Europe, Atmos. Environ., 34, 1487-1496, 2000.

Zieger, P., Kienast-Sjögren, E., Starace, M., von Bismarck, J., Bukowiecki, N., Baltensperger, U., Wienhold, F. G., Peter, T., Ruhtz, T., Collaud Coen, M., Vuilleumier, L., Maier, O., Emili, E., Popp, C., and Weingartner, E.: Spatial variation of aerosol optical properties around the high-alpine site Jungfraujoch (3580 m a.s.1.), Atmos. Chem. Phys., 12, 72317249, doi:10.5194/acp-12-7231-2012, 2012. 